\title{
Mechanisms of Summertime Subtropical Southern Indian Ocean Sea Surface Temperature Variability: On the Importance of Humidity Anomalies and the Meridional Advection of Water Vapor*
}

\author{
A. M. Chiodi And D. E. Harrison \\ Joint Institute for the Study of the Atmosphere and the Ocean, University of Washington, and NOAA/Pacific Marine Environmental \\ Laboratory, Seattle, Washington
}

(Manuscript received 23 May 2006, in final form 29 January 2007)

\begin{abstract}
It is well known that some austral summertime subtropical Indian Ocean sea surface temperature (SST) variability correlates with rainfall over certain regions of Africa that depend on rainfall for their economic well-being. Recent studies have determined that this SST variability is at least partially driven by latent heat flux variability, but the mechanism has not been fully described. Here, the mechanism that drives this SST variability is reexamined using analyses of operational air-sea fluxes, ocean mixed layer modeling, and simple atmospheric boundary layer physics. The SST variability of interest is confirmed to be mainly driven by latent heat flux variability, which is shown, for the first time, to be mainly caused by near-surface humidity variability. This humidity variability is then shown to be fundamentally driven by the anomalous meridional advection of water vapor. The meridional wind anomalies of interest are subsequently found to occur when the subtropical atmospheric anticyclone is preferentially located toward one of the sides (east/ west) of the basin.
\end{abstract}

\section{Introduction}

In many South African countries, agricultural production depends largely upon summer rainfall, which is known to have levels of interannual variability that are a large fraction of the annual mean (see Mason and Jury 1997 for a review). Understanding rainfall variability in these regions is important because times of drought can adversely affect the economic well-being of tens of millions of people. Statistical methods have connected rainfall variability in many of these African countries with subtropical Indian Ocean SST anomalies. It has also been shown that prescribed Indian Ocean SST anomalies drive realistic rainfall anomalies in atmospheric models (Rocha and Simmonds 1997b; Reason and Mulenga 1999; Reason 2001; Goddard and

\footnotetext{
* PMEL Contribution Number 2927 and Joint Institute for the Study of the Atmosphere and the Ocean Contribution Number
} 1321.

Corresponding author address: A. M. Chiodi, NOAA/Pacific Marine Environmental Laboratory, 7600 Sand Point Way NE, Box 357941, Seattle, WA 98115.

E-mail: chiodi@ocean.washington.edu
Graham 1999). This has led to a recent interest in determining the cause of these subtropical SST anomalies (cf. Behera and Yamagata 2001; Fauchereau et al. 2003; Suzuki et al. 2004; Hermes and Reason 2005). Latent heat variability, other components of surface heat flux, and ocean processes have all been implicated in forming these SST anomalies previously (Walker 1990; Yu and Rienecker 1999; Behera and Yamagata 2001; Suzuki et al. 2004; Hermes and Reason 2005), although the strongest case has been made for latent heat flux variability being the main cause of these subtropical SST anomalies. ${ }^{1}$ Preliminary results, presented herein, confirm that latent heat flux variability is the main cause of these SST anomalies. This raises the question of what causes this latent heat flux variability. It has been suggested that modulations of the subtropical atmospheric anticyclone are responsible, although the link between atmospheric variability (i.e., anticyclone modulation) and SST variability has not been precisely

\footnotetext{
${ }^{1}$ Hermes and Reason (2005) have also hypothesized that the geographical shape of the basin possibly favors the formation of dipolelike SST anomalies, although no evidence for a geographybased mechanism was given by these authors.
}

DOI: $10.1175 / J C L I 4271.1$ 


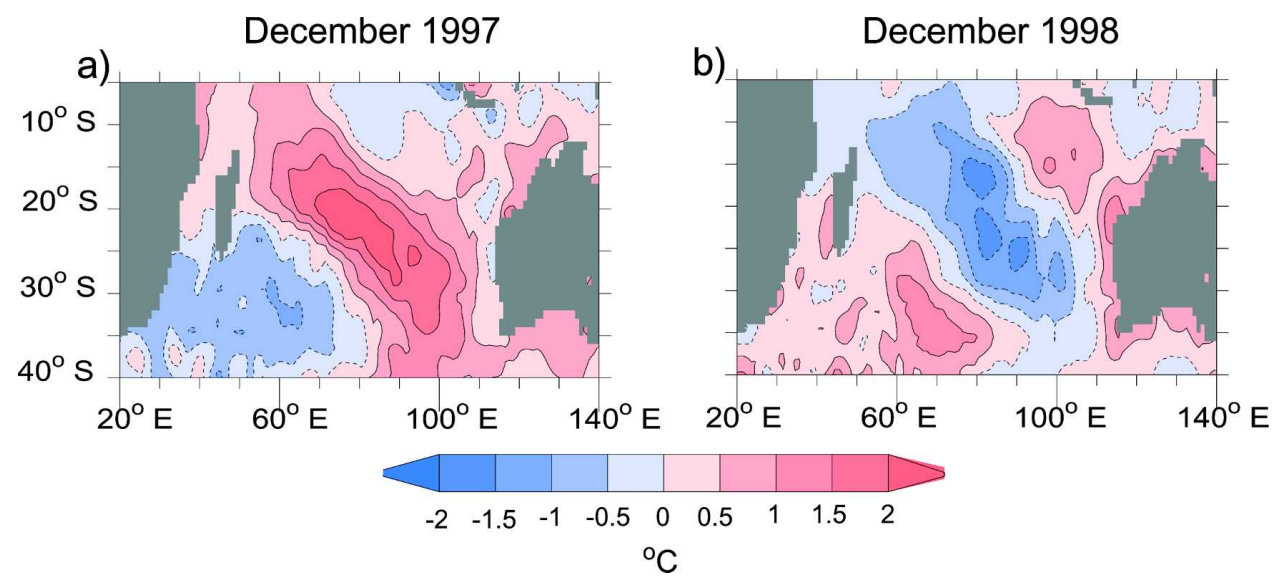

FIG. 1. December monthly mean SST anomaly (a) 1997 and (b) 1998. Reference period is 1990-2004. Data are from NOAA OISST.

determined. Investigations that have discussed the mechanism of these SST anomalies in detail have linked this latent heat flux variability to wind speed variability (e.g., Suzuki et al. 2004; Behera and Yamagata 2001). Here we reexamine the anomaly formation mechanism. Latent heat flux is parameterized in terms of two main variables [wind speed $(S)$ and the surface $\left(q_{s}\right)$ to near-surface $\left(q_{a}\right)$ difference in specific humidity $\left.\left(\Delta q=q_{s}-q_{a}\right)\right]$, but the role of $\Delta q$ anomalies has not been thoroughly investigated. It will be shown here that (i) $\Delta q$ anomalies are usually the main cause of this latent heat variability, (ii) the $\Delta q$ anomalies of interest are driven by the meridional advection of water vapor, (iii) the formation of the SST anomalies is characterized by abrupt austral summer warming that occurs when moist near-tropical air is advected southward along the western flank of the subtropical anticyclone, and (iv) the position of the subtropical atmospheric anticyclone largely determines the character of these SST anomalies.

SST variability in the subtropical southwestern Indian Ocean (the region south of Madagascar, $30^{\circ}-45^{\circ} \mathrm{S}$, $45^{\circ}-75^{\circ} \mathrm{E}$ ) is known to be positively correlated with rainfall in various regions of southern Africa (cf. Walker 1990; Rocha and Simmonds 1997b; Reason and Mulenga 1999; Reason 1999; Goddard and Graham 1999; Behera and Yamagata 2001). SST nearer the center of the subtropical basin has been shown to be inversely correlated with rainfall in these same regions of Africa. Furthermore, SST anomaly patterns that have an anomaly of one sign in the southwest and another sign midbasin (e.g., Fig. 1) are seen in spring and early summer of individual years (Reason 1999; Hermes and Reason 2005) and are present in statistical decompositions of SST data (Behera and Yamagata 2001; Fauchereau et al. 2003). Recent work has determined that the cooling and warming tends to happen simultaneously (Suzuki et al. 2004; Hermes and Reason 2005).

Warm (cool) SST anomalies have tended to occur in the southwestern (midbasin) subtropics in the austral spring to early summer of La Niña years, and the opposite pattern has tended to occur during spring/ summer of El Niño years. Both types of anomalies, however, can be seen in years which are neither El Niño nor La Niña (cf. Nicholson 1997; Reason 1999; Behera and Yamagata 2001). The rainfall-SST correlation is present even when El Niño and La Niña years are deleted from the datasets (Rocha and Simmonds 1997a; Walker 1990).

Some recently described tropical Indian Ocean variability has been found to have a roughly similar relationship to El Niño-Southern Oscillation (ENSO) variability (Huang and Kinter 2002; Saji and Yamagata 2003) as the subtropical SST variability discussed here. Important aspects of this tropical Indian Ocean SST variability have been shown to be driven by remotely forced ocean dynamics, such as equatorial Rossby waves [see Xie et al. (2002) and Behera et al. (2000), for comparison; experiments showing the purely $1 \mathrm{D}$ ocean response to ENSO-related atmospheric variability can be found in Alexander et al. (2002)]. Although the formation mechanism of the subtropical SST anomalies discussed here (described below) is different than many of those that have been shown to be prevalent in the Tropics (e.g., Xie et al. 2002), the tendency for each to coincide with ENSO variability suggests that both may be ultimately driven by coupled air-sea interaction.

Tripolar interannual SST anomalies, roughly similar in pattern to the ones described here, have been discussed recently by England et al. (2006). In this case, the SST anomalies were found using the National Oceanic and Atmospheric Administration (NOAA) Ex- 
tended Reconstructed SST composites based on annual rainfall extremes in southwest Western Australia. These SST anomalies were found to have an annual time scale and magnitudes up to $0.5^{\circ} \mathrm{C}$. They were found to be driven by a variety of geographically dependent processes, including Ekman advection and surface heat flux variability. Meridional wind variability was found to be important to some of the surface heat flux variability described by England et al., although the mechanism responsible was not discussed in detail.

An example of the SST anomaly pattern examined here can be seen in the summer months of November 1998 through February 1999, when warm SST anomalies $\left(0.5^{\circ}-1.5^{\circ} \mathrm{C}\right)$ were observed south and southeast of Madagascar (e.g., Fig. 1b). A negative SST anomaly of similar magnitude, stretching from approximately $15^{\circ} \mathrm{S}$, $50^{\circ} \mathrm{E}$ to $30^{\circ} \mathrm{S}, 100^{\circ} \mathrm{E}$ was also observed at this time. The northwest to southeast slant of this midbasin anomaly is a typical characteristic of these SST anomalies. The opposite pattern of warm midbasin-cool southwestern anomaly was observed in the summer of 1997/98 (e.g., Fig. 1a). In this case, the midbasin positive anomaly exceeded $2^{\circ} \mathrm{C}$.

We focus our analysis on the processes at work in late spring to early summer. This time of year was chosen because the link between SST and rainfall is known to be strongest at this time and also because the SST anomalies in question have been shown to depend primarily upon late spring to early summer heat flux anomalies. Two recent years in which the SST pattern in question was observed are used as case examples. Composites, formed by averaging data from many different years, are also used to check the robustness of the case study results.

It will be shown that the mechanism discussed here applies to a range of time scales (biweekly to seasonal or longer). Although the phenomena discussed here have traditionally been considered on a seasonal or longer time scale, phenomena are mainly examined here at biweekly or monthly resolution. This time scale is used because many details of the atmospheric variability discussed here are comparatively obscured by averaging over a season or longer.

This paper is organized as follows. Section 2 describes the data and ocean mixed layer model used herein. Section 3 describes ocean model case study experiments. Section 4 examines $\Delta q, S$, and latent heat variability from a numerical weather prediction model. Section 5 discusses the prevalent atmospheric phenomena and identifies a relevant sea level pressure (SLP) index. Section 6 delineates the temporal variability of this SLP index. Section 7 more thoroughly examines the anomaly formation mechanism. Section 8 provides a summary and discussion.

\section{Data and ocean mixed layer model}

Daily mean net surface heat fluxes, momentum fluxes, and precipitation were obtained from the National Centers for Environmental Prediction (NCEP) reanalysis project (available online at http://www.cdc. noaa.gov). The NCEP fluxes are estimated on a Gaussian grid (approximately $2^{\circ} \times 2^{\circ}$ ) from a global atmospheric model supplied with conventional as well as satellite-based data (Kalnay et al. 1996). The fluxes are not generally measured by conventional methods and may be thought of as model estimates that are constrained by data supplied to the model. The components of $10-\mathrm{m}$ wind (V), 2-m $q_{a}$, and surface skin temperature were also obtained from the NCEP reanalysis. Surface humidity was estimated with skin temperature, assuming that the surface is saturated.

The variable $\Delta q$ from the NCEP model depends upon the modeled values of $q_{a}$, which are not generally constrained by observations and thus may contain errors due to imperfections in the model. Smith et al. (2001) found that, at 6-h resolution, the root-meansquare (rms) difference between $q_{a}$ from high-quality in situ measurements (World Ocean Circulation Experiment, 1990-95) and from the NCEP reanalysis was 1.3 $\mathrm{g} \mathrm{kg}^{-1}$. The NCEP reanalysis also showed an average warm bias that was on the order of $0.1 \mathrm{~g} \mathrm{~kg}^{-1}$. Given climatological subtropical bulk flux parameters (e.g., $1.2 \mathrm{~kg} \mathrm{~m}^{-3}$ air density; $6 \mathrm{~m} \mathrm{~s}^{-1}$ wind speed) the 1.3 $\mathrm{g} \mathrm{kg}^{-1}$ error in $q_{a}$ reported by Smith would account for a random error of about $30 \mathrm{~W} \mathrm{~m}^{-2}$ in the 6-hourly latent heat flux. This rms difference should be reduced 10 -fold in the monthly mean averages discussed here because roughly 120 6-h samples are averaged per month. The latent heat flux anomalies discussed below are about twice as large as the $30 \mathrm{~W} \mathrm{~m}^{-2}$ error associated with Smith's description of 6-hourly $q_{a}$ error. Thus at monthly time scales, the signal-to-noise ratio is favorable for the analysis described herein.

NOAA optimally interpolated SST (OISST) was obtained from the NOAA Climate Diagnostics Center (available online at http://www.cdc.noaa.gov). OISST is a weekly dataset that merges in situ and satellite-based SST observations (Reynolds et al. 2002).

For comparison purposes, SST was reproduced by integrating the surface flux fields in an ocean mixed layer model (Price et al. 1986). The model used here was configured to resolve the upper $500 \mathrm{~m}$ of the water column. Initial conditions were taken from the Levitus (1994) climatology. This model deepens the mixed 
layer (thereby entraining deeper water) when vertical shear exceeds a critical bulk Richardson number (0.65) or when static instability occurs. Stratification is restored based on buoyancy input from freshwater or a net flux of heat into the ocean. Penetrative shortwave radiation is assumed to consist of two components, absorbed with $0.6-$ and $20-\mathrm{m} e$-folding scales, respectively (Paulson and Simpson 1977). All other surface fluxes are applied entirely to the mixed layer. Integrations are performed with vertical resolution set at $1 \mathrm{~m}$ in order to well resolve shallow summertime mixed layer depths. A background diffusion of $2 \times 10^{-5} \mathrm{~m}^{2} \mathrm{~s}^{-1}$ is applied uniformly throughout the water column. The diffusion acts to lower unreasonably high SSTs, which may occur in the model when very thin mixed layers develop during summer. The diffusion may be thought of as a crude stand in for unresolved processes, such as internal wave breaking. Integrations begin in the austral winter and are carried out through summer. Experiments have shown that the results presented here are not sensitive to initial conditions, so long as the starting temperature profile is reasonable, for example, the mixed layer is deep to begin with and the mixed layer temperature is within several degrees of observed SST.

The effects of surface currents on SST tendency were examined using currents from the Simple Ocean Data Assimilation (SODA; available online at http:// www.atmos.umd.edu). Currents from SODA were used for this purpose because, unlike currents from the mixed layer model described above, they contain geostrophic components (Carton et al. 2000).

\section{Ocean mixed layer model results}

To test whether surface fluxes drive the SST anomalies of interest here, and whether the processes that cause this surface flux variability are well resolved in the NCEP reanalysis, we have compared observed temperature tendencies with tendencies predicted from an ocean mixed layer model forced with NCEP surface fluxes. Case studies of two recent examples are described here.

Observations show that the warm SST anomalies seen in December of 1997 and 1998 (Fig. 1) are largely driven by changes in SST that occur in November of 1997 and 1998, respectively. These SST changes are characterized by abrupt warming in specific coherent regions that cover much $(2500 \mathrm{~km})$ but not all of the basin. These warming regions appear in a different location in each case. For example, abrupt warming of SST $\left(2^{\circ}-4^{\circ} \mathrm{C}\right)$ was observed in the central subtropics (centered around $20^{\circ} \mathrm{S}, 75^{\circ} \mathrm{E}$ ) during November of 1997 (Fig. 2a). Similarly, abrupt warming was also observed during November of 1998, although, in this case, the $2^{\circ}-4^{\circ} \mathrm{C}$ warming was seen in the southwestern subtropics (centered around $35^{\circ} \mathrm{S}, 55^{\circ} \mathrm{E}$ in Fig. 2b). Monthly warming of the same large spatial scale and magnitude was not observed in either October 1997 or October 1998 (not shown). ${ }^{2}$

The observation of abrupt November SST warming that is roughly collocated with warm December SST anomalies supports the findings of Suzuki et al. (2004) who claim that these anomalies form in late spring to early summer because the ocean mixed layer depth is shallow then, making SST highly sensitive to surface heat flux anomalies.

Many aspects of the observed SST tendencies are reproduced in the ocean mixed layer model. Most importantly, coherent regions that warm abruptly and have similar shape, location, and amplitude as observations are clearly seen in model SST. In 1997, for example, the shape and magnitude of the coherent, abrupt warming region seen in the observations $\left(20^{\circ} \mathrm{S}\right.$, $70^{\circ} \mathrm{E}$ ) is reasonably well reproduced by the model (Fig. 2c). SST increases by $>2^{\circ} \mathrm{C}$ during November 1997 in the regions east of Madagascar $\left(22^{\circ} \mathrm{S}, 60^{\circ} \mathrm{E}\right)$ and west of Australia $\left(25^{\circ} \mathrm{S}, 93^{\circ} \mathrm{E}\right)$ in the model, as it does in observations. Some discrepancies are apparent between the model and the observations. In 1997, for example, the warming tendency is overpredicted at $22^{\circ} \mathrm{S}, 60^{\circ} \mathrm{E}$ and underpredicted at $25^{\circ} \mathrm{S}, 85^{\circ} \mathrm{E}$. These discrepancies may be caused by errors in the fluxes or model physics. Despite these possible sources of error, the overall temperature tendency predicted by the model correlates well with observations (spatial correlation is 0.78 for November 1997 and 0.72 for November 1998 in the region $10^{\circ}-40^{\circ} \mathrm{S}$ and $\left.20^{\circ}-140^{\circ} \mathrm{E}\right)$. Note that in the southwestern subtropics $\left(33^{\circ} \mathrm{S}, 50^{\circ} \mathrm{E}\right)$ warming of less than $0.5^{\circ} \mathrm{C}$ or cooling is seen in both the model and observations during November 1997, whereas during November 1998, both model and observations show warming of $>2^{\circ}$ in this location. Also note that during November 1998, neither the observations nor model show warming $>1^{\circ}$ in the central subtropical region that was observed to warm abruptly during November 1997. The fidelity of the model results discussed here strongly suggests that the SST anomalies in question are driven by surface fluxes of heat and/or momentum.

Surface momentum flux anomalies can drive SST anomalies by causing entrainment of water below the

\footnotetext{
${ }^{2}$ Localized warming of $2^{\circ}-3^{\circ} \mathrm{C}$ was observed at $34^{\circ} \mathrm{S}, 85^{\circ} \mathrm{E}$ during October 1997, but this warming was smaller in spatial scale and magnitude than the warming seen in November. No southern subtropical Indian Ocean region was observed to warm by more than $2^{\circ} \mathrm{C}$ during October 1998 .
} 

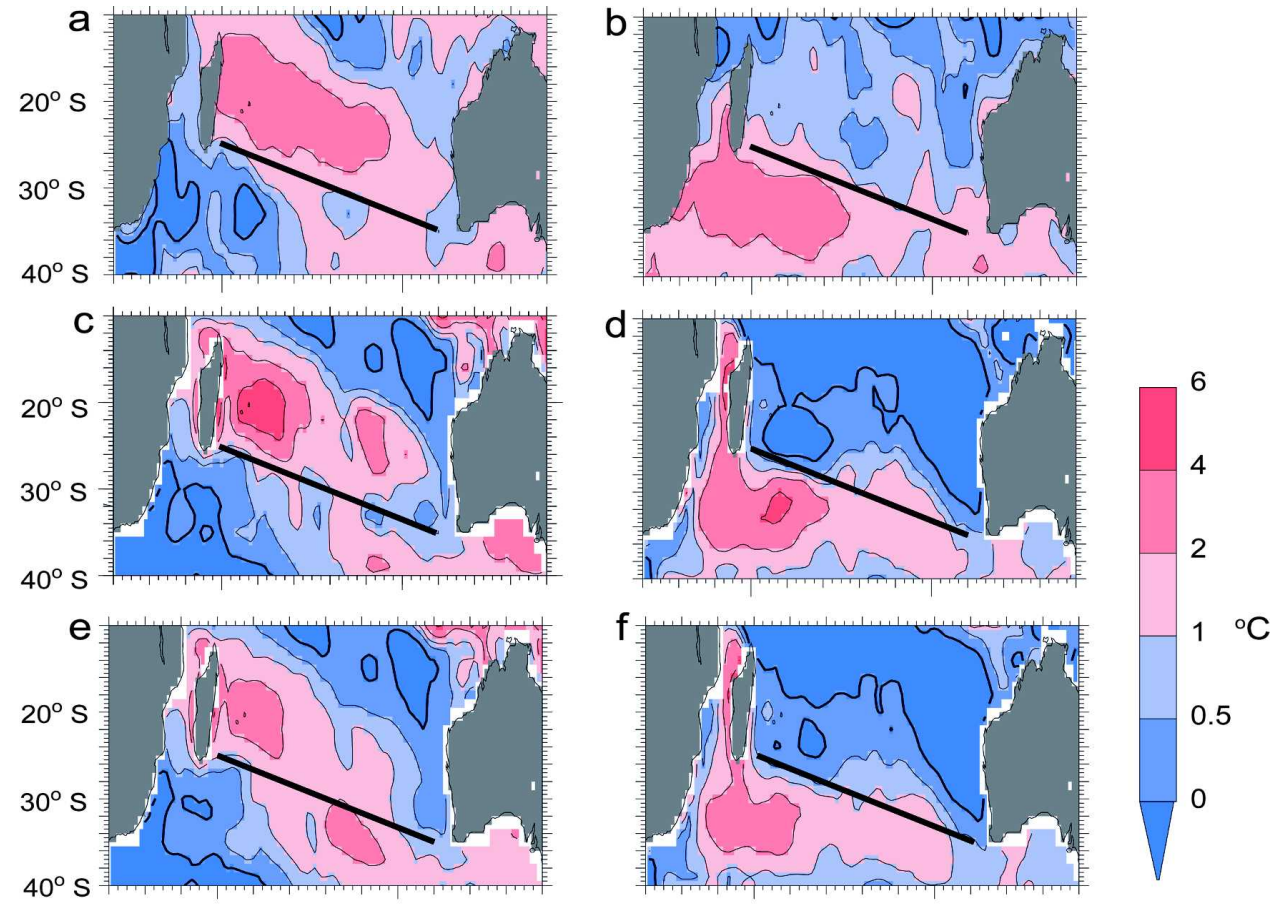

${ }^{\circ} \mathrm{C}$
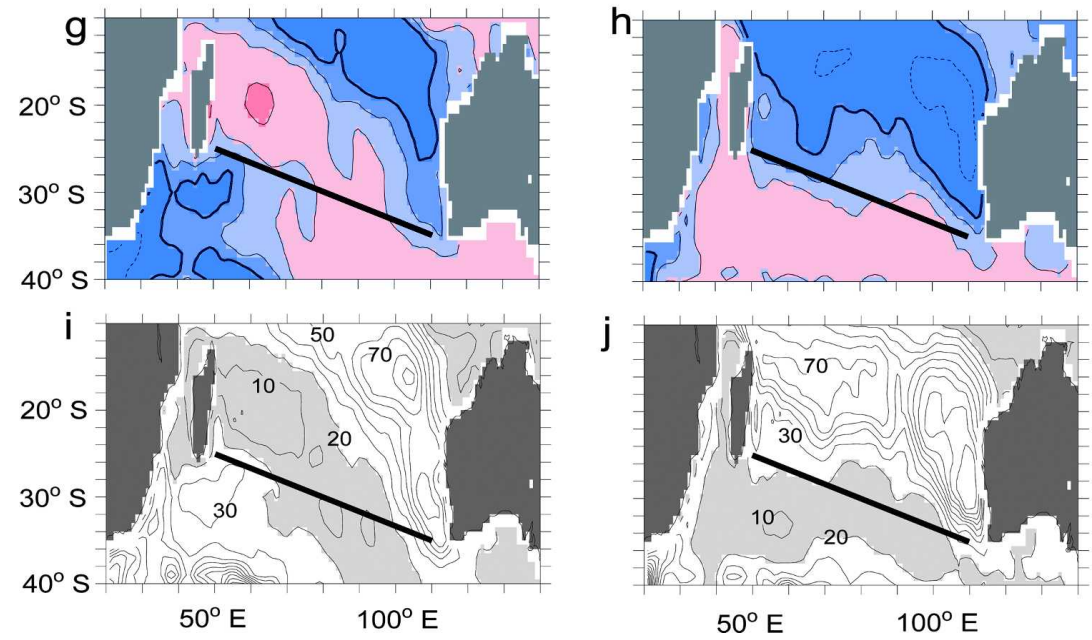

FIG. 2. Observed temperature change between 1-30 Nov (a) 1997 (b) 1998. (c) As in (a), except the temperature change is estimated by an ocean mixed layer model using NCEP surface fluxes. (d) As in (c), except for 1998. (e) As in (c), except the climatological monthly mean momentum flux, rather than the daily mean momentum flux is used. (f) As in (e), except for 1998. (g) Model run similarly to (c), except that the mixed layer depth is fixed at $35 \mathrm{~m}$. (h) As in (g), except for 1998. (i) Mean November 1997 model mixed layer depth. Contour interval is $10 \mathrm{~m}$. Depths less than $20 \mathrm{~m}$ are shaded light gray. (j) As in (i), except for 1998. The straight black line is drawn to roughly mark the division between the observed anomalous warming and cooling regions.

mixed layer and/or by affecting the mixed layer depth, which controls the sensitivity of SST to surface heat flux anomalies. The model experiments described below show that, although momentum anomalies contribute to the SST anomalies discussed here, these SST anomalies are not fundamentally caused by momentum anomalies. When momentum anomalies are removed from the forcing-by using climatological monthly mean wind stress (period 1992-2004) rather than daily mean wind stress - the shape and amplitude of the SST anomalies change by a relatively small amount. In the 1998 case, the average warming amplitude in the southwestern subtropics changes by only about $10 \%$ (Fig. 2f). In 1997, wind stress variability has slightly 


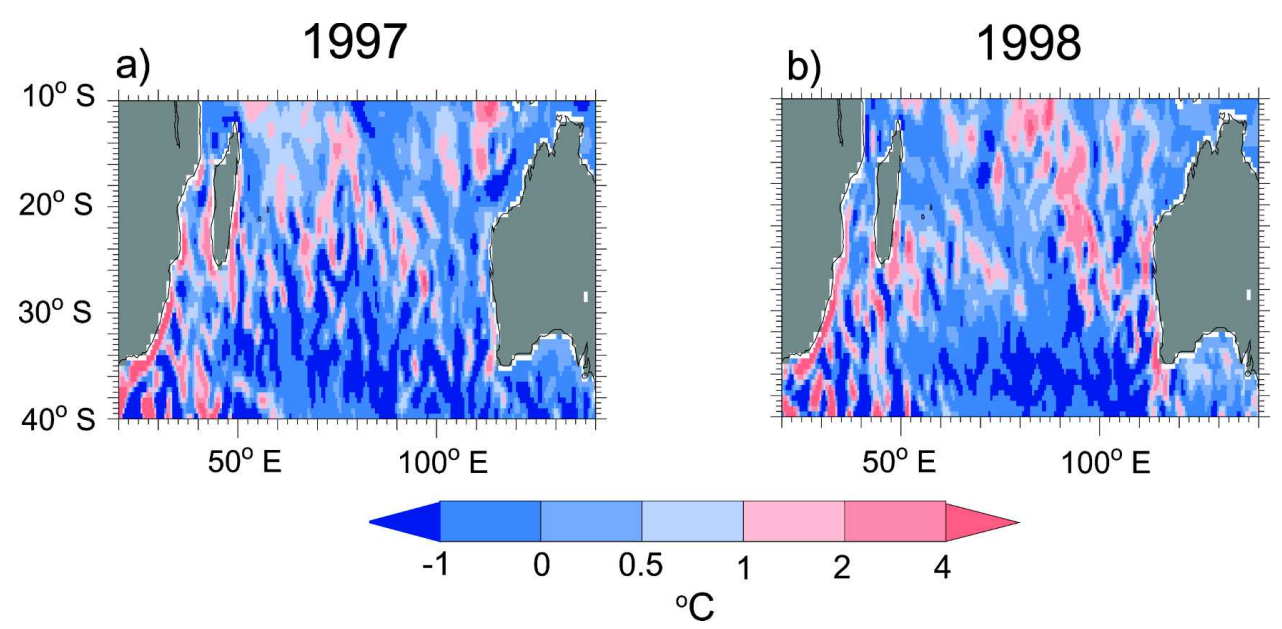

FIG. 3. Estimated temperature tendency (change from 1-30 Nov) due to SODA surface currents during November (a) 1997 and (b) 1998.

more effect on the modeled temperature tendency (Fig. 2e). Most notably, warming at $35^{\circ} \mathrm{S}, 90^{\circ} \mathrm{E}$ is enhanced while warming at $25^{\circ} \mathrm{S}, 93^{\circ} \mathrm{E}$ is diminished. The general pattern of low warming to cooling in the southwest and abrupt warming in the central basin, however, is preserved in the 1997 run that excludes wind stress variability. The results of these model experiments show that heat flux anomalies mainly drive the temperature tendencies seen in the model. This result is consistent with previous studies of the effects of wind stress and heat flux variability on tropical/subtropical Atlantic (Carton et al. 1996) and Indian Oceans (Behera et al. 2000) SST variability.

It is notable that the warming tendencies discussed above are significantly larger than the cooling tendencies. This occurs even though the positive and negative surface heat flux anomalies that drive these tendencies have similar magnitudes (as described below). Model results suggest that warming tendencies are larger partly because the ocean mixed layer tends to shoal in response to incoming heat flux anomalies. Thus, incoming heat anomalies are spread over a thinner mixed layer and thereby produce larger changes in SST. This can be seen by comparing the mixed layer depth estimated by the model in each case. Averaged over 1997, for example, the model mixed layer depth is less than 20 $\mathrm{m}$ deep throughout much of the central basin region and deeper than $30 \mathrm{~m}$ in much of the southwestern basin (Fig. 2i). In the 1998 case, however, the model mixed layer is considerably deeper than $30 \mathrm{~m}$ in much of the central basin region and less than $20 \mathrm{~m}$ deep in the majority of the southwestern basin (Fig. 2j). Correspondingly, peak warming is reduced by factors of $2-3$ in the runs with mixed layer depths held fixed at $35 \mathrm{~m}$ (roughly the model average for November).
The effects of ocean surface currents during November 1997 and 1998 have been estimated but found to play a secondary role, at best, in the formation of the SST anomalies discussed here. The advective temperature tendency is found by integrating surface temperature advection (currents from SODA; SST gradients from NOAA OISST) from 1 to 30 November. In either case, the advective temperature tendencies (Figs. 3a,b) do not appear to have the same coherent patterns that appear in the observed net SST tendencies (Figs. 2a,b). Currents from the ocean mixed layer model runs were also used to estimate the advective temperature tendencies (computed as per Price et al. 1986). These tendencies also were found to lack the patterns necessary to drive the observed SST anomalies and are not shown for brevity.

A comparison of the heat flux anomalies estimated by the NCEP reanalysis quickly reveals that only latent heat flux anomalies have the magnitude and pattern necessary to drive the observed SST anomalies (Fig. 4; see also Behera and Yamagata 2001; Suzuki et al. 2004; Hermes and Reason 2005). In 1997, a pattern commensurate to the warm central basin-cool southwestern basin December 1997 SST anomaly was apparent in the November NCEP latent heat flux anomaly; the November 1997 latent heat flux anomaly has a midbasin minimum $\left(40-80 \mathrm{~W} \mathrm{~m}^{-2}\right)$ centered at $20^{\circ} \mathrm{S}, 65^{\circ} \mathrm{E}$ that extends toward the southeast, such that low anomalies of $20-40 \mathrm{~W} \mathrm{~m}^{-2}$ are seen throughout most of the central Indian Ocean, between $20^{\circ}$ and $28^{\circ} \mathrm{S}$ (Fig. 4a). A maximum in latent heat loss $\left(20-60 \mathrm{~W} \mathrm{~m}^{-2}\right)$ is also apparent in the southwestern subtropics $\left(30^{\circ} \mathrm{S}, 50^{\circ} \mathrm{E}\right)$ in 1997. Thus, by NCEP estimates, the oceanic region east of Madagascar gained up to $80 \mathrm{~W} \mathrm{~m}^{-2}$ more than usual in November 1997, while the southwestern subtropics lost 

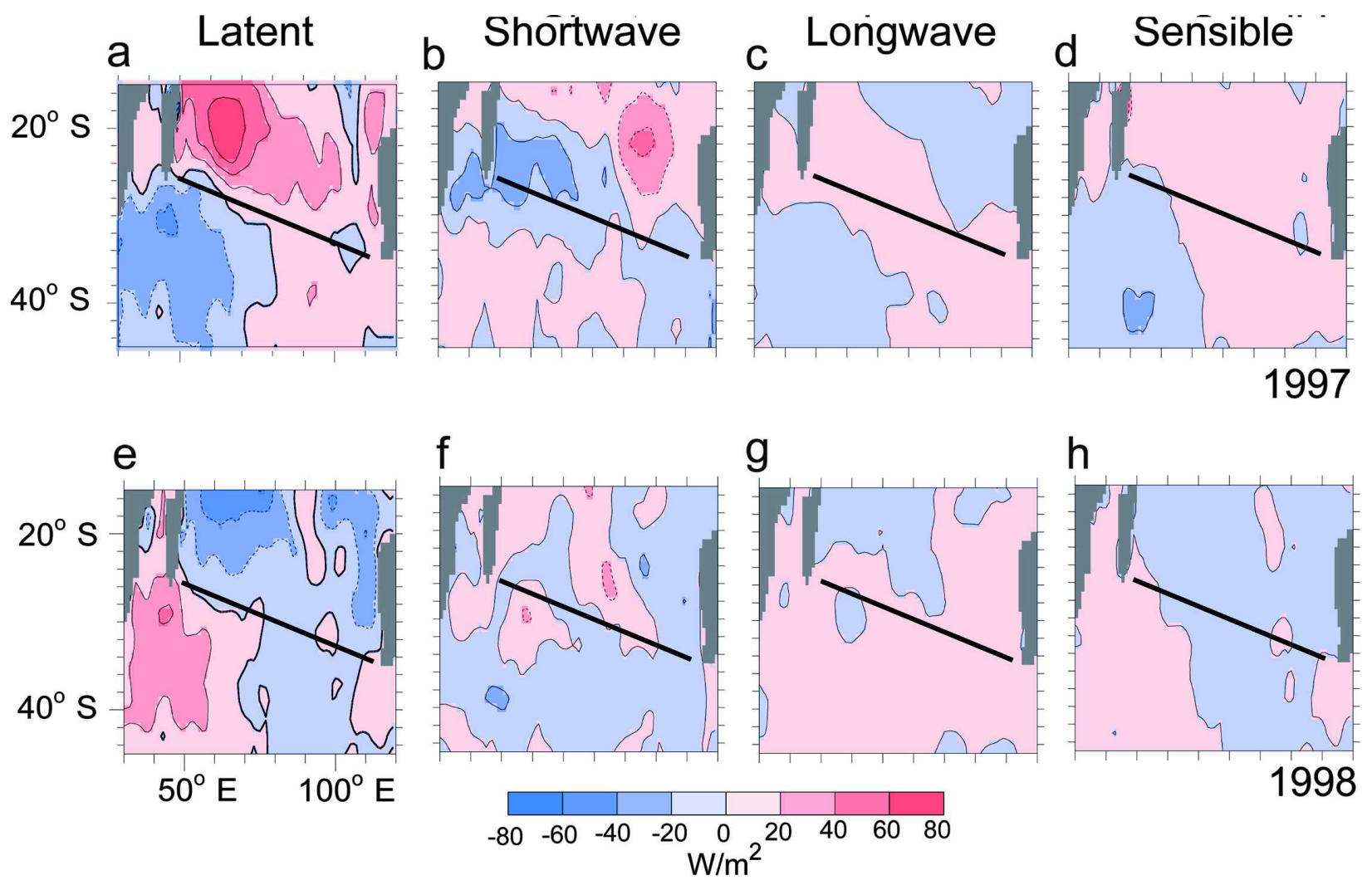

FIG. 4. Average net surface anomaly values for 1-30 Nov 1997: (a) latent heat flux, (b) shortwave radiation, (c) longwave radiation, and (d) sensible heat flux. (e)-(h) are the same as (a)-(d), except for 1998. Downward anomalies are positive. The straight black line roughly marks the division between regions of observed anomalous warming and cooling (see Fig. 2).

up to $60 \mathrm{~W} \mathrm{~m}^{-2}$ more than the monthly climatological average. The latent heat flux anomaly that appears in November of 1998, in many regards, is opposite that of November 1997 (Fig. 4e). Again, a dipole pattern is apparent between the southwest and central subtropics in 1998, but the pattern is reversed with respect to 1997 so that $40-80 \mathrm{~W} \mathrm{~m}^{-2}$ less heat than usual is lost over most of the southwest and $20-60 \mathrm{~W} \mathrm{~m}^{-2}$ more is lost in the central subtropics. Note that the magnitudes of the sensible and longwave heat flux anomalies are much smaller than the latent heat flux anomaly and therefore play secondary roles in creating SST anomalies (Figs. $4 \mathrm{c}, \mathrm{d}, \mathrm{g}, \mathrm{h})$. Note also that the patterns seen in the shortwave anomalies do not have the shape needed to drive the SST anomalies discussed here (Figs. 4b,f).

In summary, observations indicate that abrupt warming occurs in November, leading up to the warm anomalies observed in December. Mixed layer model integrations of NCEP-derived heat fluxes reproduce the location and general magnitude of this warming, and only latent heat flux anomalies are of appropriate magnitude and pattern to drive the SST anomalies in question.

\section{The relationship between $\Delta q, S$, and latent heat flux variability in the NCEP reanalysis}

In this section we compare the relative effects of wind speed and $\Delta q$ anomalies on latent heat flux. First, a formal relationship is found from a simple perturbation analysis of the bulk parameterization of latent heat flux (e.g., Large and Pond 1981):

$$
Q_{\mathrm{LH}}=C_{e} L_{e} \rho S \Delta q,
$$

where $C_{e}$ is the exchange coefficient, $L_{e}$ is the latent heat of vaporization, and $\rho$ is air density. It is straightforward to find that

$$
\frac{Q_{\mathrm{LH}}^{\prime}}{\overline{Q_{\mathrm{LH}}}} \approx \frac{\Delta q^{\prime}}{\overline{\Delta q}}+\frac{S^{\prime}}{\bar{S}}
$$

(appendix A). Here, $Q_{\mathrm{LH}}^{\prime}$ is the monthly latent heat anomaly with respect to the monthly mean climatology $\overline{Q_{\mathrm{LH}}}$ (with similar notation for $S$ and $\Delta q$ ).

For the remainder of the paper, we will use the absolute value of the ratio 
a
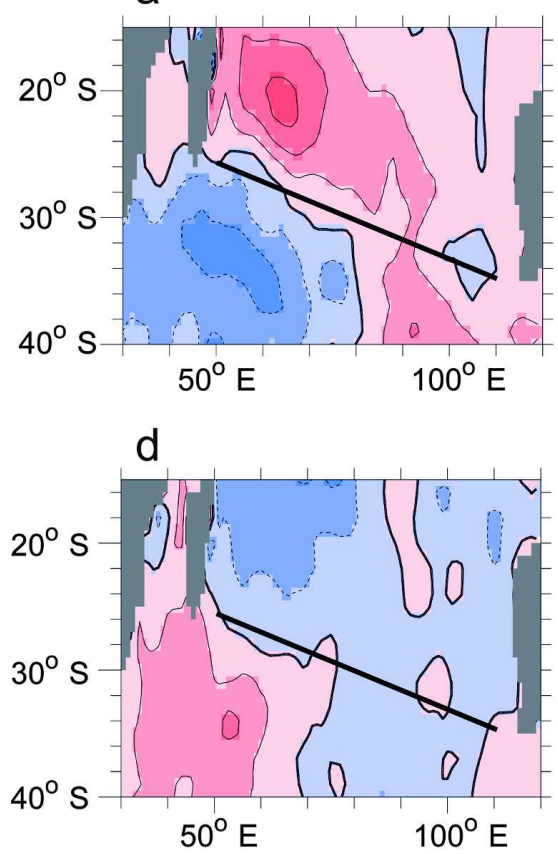

b
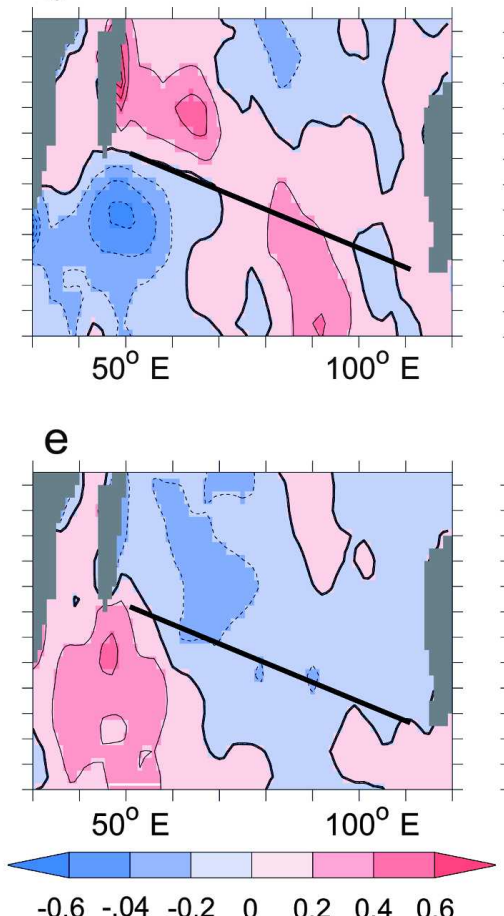

C
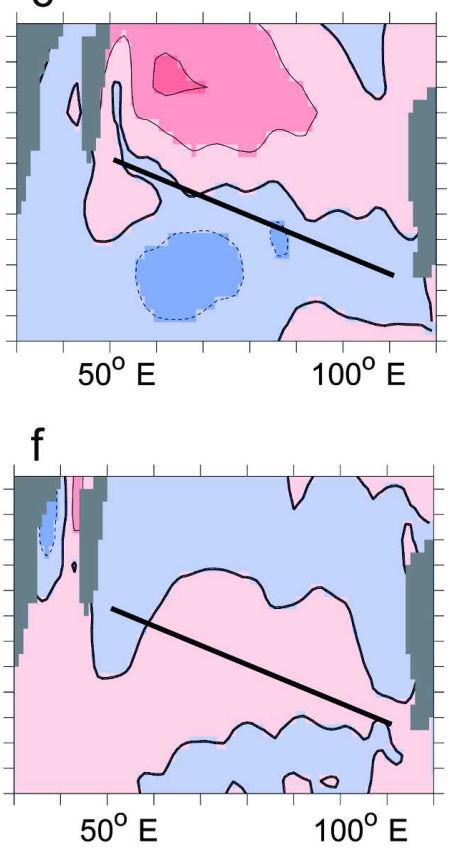

FIG. 5. November 1997 mean (a) $r_{\mathrm{LH}}$, (b) $r_{\Delta q}$, and (c) $r_{s}$. (d)-(f) As in (a)-(c), except for 1998. Anomalies that would tend to cause anomalous warming of SST are positive (red). The straight black line roughly marks the division between regions of observed anomalous warming and cooling (see Fig. 2).

$$
R=\frac{\frac{\Delta q^{\prime}}{\overline{\Delta q}}}{\frac{\overline{S^{\prime}}}{\bar{S}}}
$$

to determine the primacy of these terms. Since the variables in Eq. (2) are all readily available from the NCEP reanalysis, this method provides a quantitative measure of the relative importance of $\Delta q^{\prime}$ and $S^{\prime}$ to $Q_{\mathrm{LH}}^{\prime}$. To be more concise hereafter, we define

$$
\begin{aligned}
r_{\mathrm{LH}} & \equiv \frac{Q_{\mathrm{LH}}^{\prime}}{\overline{Q_{\mathrm{LH}}}} \\
r_{s} & \equiv \frac{S^{\prime}}{\bar{S}}, \quad \text { and } \\
r_{\Delta q} & \equiv \frac{\Delta q^{\prime}}{\overline{\Delta q}} .
\end{aligned}
$$

Consider the dipolelike pattern apparent in the November 1997 NCEP latent heat flux anomaly (Fig. 4a). Equation (2) tells us that a commensurate dipolelike pattern must be present in either $r_{\Delta q}, r_{s}$, or their sum. Such a pattern is clearly seen in the November $1997 \Delta q$ anomaly (Fig. 5b). A maximum and minimum appear in $r_{\Delta q}$ at roughly the same locations as the previously men- tioned latent heat extrema. Furthermore, $\Delta q$ in the southwestern subtropics is $20 \%-60 \%$ less than the climatological monthly mean. This same dipole pattern is not so apparent in the November $1997 S$ anomaly (Fig. 5c). Although an $S$ minimum $(40 \%-60 \%$ lower than normal) appears at roughly the same location as the midbasin latent heat flux minimum $\left(20^{\circ} \mathrm{S}, 60^{\circ} \mathrm{E}\right)$, a slight local $S$ minimum $(0 \%-20 \%)$ is also shown in the southwestern subtropics $\left(30^{\circ} \mathrm{S}, 50^{\circ} \mathrm{E}\right)$, which obviously counters some of the effect of the southwestern subtropical $\Delta q$ anomaly. In this case, the southwestern latent heat flux anomaly is mainly due to $\Delta q$ variability and the midbasin anomaly depends on both $S$ and $\Delta q$ variability.

The latent heat anomaly apparent in November 1998 clearly appears to be driven by $\Delta q$ variability. Similarly to $r_{\mathrm{LH}}, r_{\Delta q}$, abruptly changes sign moving from the southwestern subtropics to the region east of Madagascar. Minimums in both heat loss and $\Delta q$ are centered near $30^{\circ} \mathrm{S}, 48^{\circ} \mathrm{E}$. As estimated by the NCEP reanalysis, $\Delta q$ was $40 \%-60 \%$ lower than average over most of the southwestern subtropics during November 1998 and $0 \%-40 \%$ larger than normal over much of the central subtropics. As in 1997, both the latent heat flux and $\Delta q$ anomaly patterns have a similar northwest to southeast orientation, whereas the wind speed anomaly is ori- 
TABLE 1. (first row) Spatial correlation of $r_{\Delta q}$ and $r_{\mathrm{LH}}$ in the Indian Ocean, $15^{\circ}$ to $45^{\circ} \mathrm{S}$. (second row) As in first row, except for $r_{s}$. (third row) Mean difference between the highest and lowest $5 \%$ of $r_{\Delta q}$ values in the Indian Ocean. (fourth row) As in third row, except for $r_{s}$.

\begin{tabular}{|c|c|c|c|c|c|c|c|c|c|c|c|}
\hline & 1993 & 1994 & 1995 & 1996 & 1997 & 1998 & 1999 & 2000 & 2001 & 2002 & 2003 \\
\hline$r_{\Delta q}-r_{\mathrm{LH}}$ correlation & 0.50 & 0.71 & 0.72 & 0.70 & 0.77 & 0.85 & 0.63 & 0.69 & 0.48 & 0.82 & 0.69 \\
\hline$r_{S}-r_{\mathrm{LH}}$ correlation & 0.41 & 0.25 & 0.54 & 0.38 & 0.61 & 0.55 & 0.53 & 0.61 & 0.49 & 0.61 & 0.54 \\
\hline$r_{\Delta q}$ range & 0.57 & 0.76 & 0.64 & 0.58 & 1.0 & 0.71 & 0.67 & 0.70 & 0.64 & 0.88 & 0.58 \\
\hline$r_{S}$ range & 0.27 & 0.30 & 0.31 & 0.27 & 0.50 & 0.26 & 0.33 & 0.36 & 0.38 & 0.33 & 0.32 \\
\hline
\end{tabular}

ented zonally. The pattern seen in $r_{s}$ has a smaller range of values than $r_{\Delta q}$; the vast majority of the wind speed anomalies are within $20 \%$ of the climatological mean.

Averaged over the region considered, there is quantitative evidence that $\Delta q^{\prime}$ is more important than $S^{\prime}$. The spatial correlations between $r_{\Delta q}$ and $r_{\mathrm{LH}}(0.77$, $0.85)$ are higher than for $r_{s}$ and $r_{\mathrm{LH}}(0.61,0.55)$ in both 1997 and 1998. The range of the $r_{\Delta q}$ is also larger than the range of $r_{s}$ (Table 1). In general, the magnitude of $r_{s}$ is 0.4 or lower, while both $r_{\mathrm{LH}}$ and $r_{\Delta q}$ reach levels of 0.8 or higher. This means that the large latent heat anomalies described here (up to $80 \mathrm{~W} \mathrm{~m}^{-2}$ ) would be unlikely to occur if wind speed were the only factor contributing to latent heat flux variability. Only two years are discussed here in detail for brevity, but analysis has shown that, compared to $r_{s}, r_{\Delta q}$ has a larger range and is more highly correlated with $r_{\mathrm{LH}}$ for all but one year (2001) between 1993 and 2003 (Table 1).

\section{Atmospheric variability}

This section describes the atmospheric phenomena that create the latent heat flux anomalies described above. Visual inspection of SLP and near-surface wind fields suggest that conditions favorable to warming are created within the central/western flank of the subtropi- cal atmospheric anticyclone; November 1998 monthly mean winds clearly show that the anticyclone is adjacent to the region of rapidly warming SST (Fig. 6b). Furthermore, November 1997 monthly mean winds show a clear shift of the anticyclone to the east (see Fig. 6a), consistent with the warming observed then. To test whether anticyclone position determines the location of the abrupt warming, we have defined a simple index for anticyclone position and asked whether or not it might be used as a proxy for the observed latent heat flux and SST anomaly patterns.

This index is based on the difference of daily mean NCEP SLP anomaly between the approximate position of the November 1998 SLP high $\left(37^{\circ}-28^{\circ} \mathrm{S}, 60^{\circ}-70^{\circ} \mathrm{E}\right)$ and the November 1997 SLP high $\left(37^{\circ}-28^{\circ} \mathrm{S}, 85^{\circ}-\right.$ $\left.100^{\circ} \mathrm{E}\right)$. This difference is smoothed with a 15 -day boxcar filter and resampled every 15 days, starting 1 January 1992, resulting in approximately 150 values. The November through March values were sorted and the 25 largest and smallest were chosen to form composites of the low-level atmosphere. Fifteen-day averages, bracketing each of these extrema, were first calculated from daily averages of the relevant atmospheric variables. Then, the averages from each group of 25 days were combined to form two composites representing the average atmospheric conditions during times in

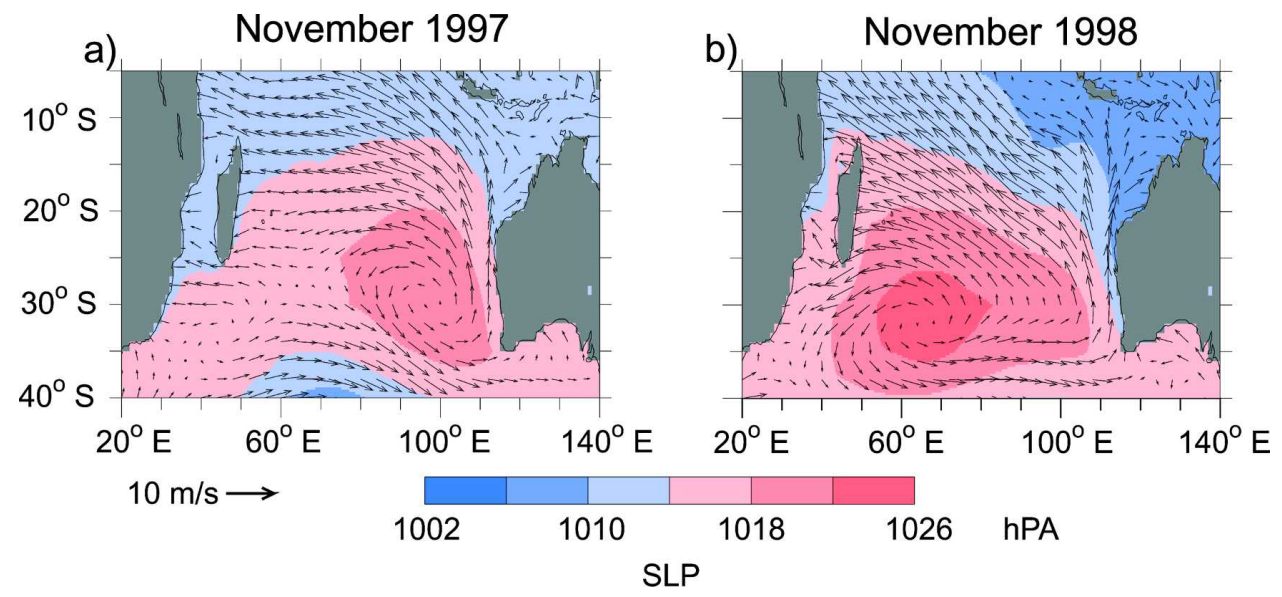

FIG. 6. November mean SLP (color field) and 10-m winds (vectors): (a) 1997 and (b) 1998. 
which the west to east SLP difference was anomalously large and small, respectively.

The high western SLP composite (Fig. 7a) clearly shows the anticyclone positioned to the west, similar to the November 1998 average conditions. Likewise, the high eastern SLP composite (Fig. 7b) shows the anticyclone positioned to the east, as in the November 1997 average. The difference of the two latent heat flux composites bears a close resemblance to the anomalies seen in 1997 and 1998 (Fig. 7c). The composite difference pattern clearly changes sign moving from the southwestern basin to the region east of Madagascar, similarly to the SST anomaly pattern in question. The poles of these SLP and latent heat flux anomalies are significant at the $90 \%$ confidence level (Figs. 7d-f; Student's $t$ method; the composite difference is shown only where both composite anomalies are significantly different from the mean).

Compositing further suggests that the meridional advection of water vapor mainly causes the latent heat flux/SST anomaly pattern discussed here since this pattern is also apparent in composite differences of meridional wind, humidity advection $\left(-\mathbf{V} \cdot \nabla_{h} q_{a}\right)$, and SST anomalies (Figs. $7 \mathrm{~g}-\mathrm{i}$, time indices are lagged 1 week for SST). For each of these variables, the anomalies that are centered in the southwestern and central basin regions are significant at the $90 \%$ confidence level. The relationship among these variables will be examined further in section 7 .

\section{Indices of atmosphere-ocean interaction}

The observed interannual variability of SST compares favorably with the SLP-based index described above. For comparison purposes, an SST anomaly index was formed by differencing two 30-day mean SST anomalies; one averaged within the southwestern region $\left(40^{\circ}-30^{\circ} \mathrm{S}, 45^{\circ}-65^{\circ} \mathrm{E}\right)$ and the other averaged within the central basin region $\left(25^{\circ}-15^{\circ} \mathrm{S}, 60^{\circ}-80^{\circ} \mathrm{E}\right)$. These regions are similar to those used previously (e.g., Hermes and Reason 2005; Behera and Yamagata 2001) to index southern subtropical Indian Ocean SST variability (a comparison is given below). This index is significantly correlated with the average November SLP index described above (Fig. 8a; 0.66 correlation; 95\% confidence level is 0.57 ; Fisher's $z$ with 12 degrees of freedom). There are some discrepancies between the SLP and SST index. For instance, large negative SLP index values do not always correspond to large negative SST index values (e.g., year 2003). Such discrepancies may reflect the inability of this simple SLP index to adequately represent all atmospheric variability. This is suggested by the higher correlations found between the
SST index and the other three indices described above $(0.90,0.83$, and 0.73 for latent heat, meridional wind, and $-\mathbf{V} \cdot \nabla q_{a}$, respectively). Discrepancies may also be due to errors in the surface fluxes or secondary sources of SST variability; however, the reasonable agreement between each of these indices suggests that the SST variability is driven by latent heat flux/meridional advection anomalies.

Results have shown that the methodology used here remains valid on seasonal time scales. For example, we have repeated the above analysis by comparing the atmospheric conditions during the seasonal onset of these anomalies (November through March) with the SST anomalies in the peak (February and March) season (this timing was originally proposed by Hermes and Reason 2005). When averaged over these times, the SLP index described above remains highly correlated to the latent heat flux, meridional wind, $-\mathbf{V} \cdot \nabla q_{a}$, and SST indices $(0.86,0.50,0.89$, and 0.75 correlations, respectively; $95 \%$ confidence level $=0.57$ ). This suggests that the interannual variability of these SST anomalies depends fundamentally on the mechanism discussed here.

Because these SST anomalies peak in somewhat different locations each year, a unique spatial definition is unlikely to capture each peak (Hermes and Reason 2005). Accordingly, the regions used for the SST index described above (based on the November 1997 and November 1998 case examples) are somewhat different than those described by Hermes and Reason $\left(44^{\circ}-30^{\circ} \mathrm{S}\right.$, $44^{\circ}-74^{\circ} \mathrm{E}$ and $\left.35^{\circ}-19^{\circ} \mathrm{S}, 80^{\circ} \mathrm{E}: 110^{\circ} \mathrm{E}\right)$ and by Behera and Yamagata (2001) $\left(37^{\circ}-27^{\circ} \mathrm{S}, 55^{\circ}-65^{\circ} \mathrm{E}, 28^{\circ}-18^{\circ} \mathrm{S}\right.$, $90^{\circ}-100^{\circ} \mathrm{E}$ Each of these indices, however, show very similar variability over the period examined here (Fig. 8c; all cross correlations are above 0.82 ).

\section{The relationship between $\Delta q, S$, and latent heat flux in an idealized atmospheric mixed layer}

In this section we examine the formation mechanism of these anomalies more closely. A simple scale analysis suggests that humidity advection $\left(-\mathbf{V} \cdot \nabla_{h} q_{a}\right)$ can easily change $\Delta q$ in the subtropics. The relevant horizontal length scale

$$
l=\frac{\Delta q}{\left|\nabla_{h} q_{a}\right|}
$$

is near $1000 \mathrm{~km}$ in the subtropics and smaller at higher latitudes (Fig. 9). Contours of $q_{a}$ closely follow contours of SST. Thus, $\nabla_{h} q_{a}$ points mainly in a northward direction and $\mathbf{V} \cdot \nabla_{h} q_{a}$ is dominated by the meridional term. This means that meridional advection associated with synoptic-scale atmospheric phenomena (length scales 

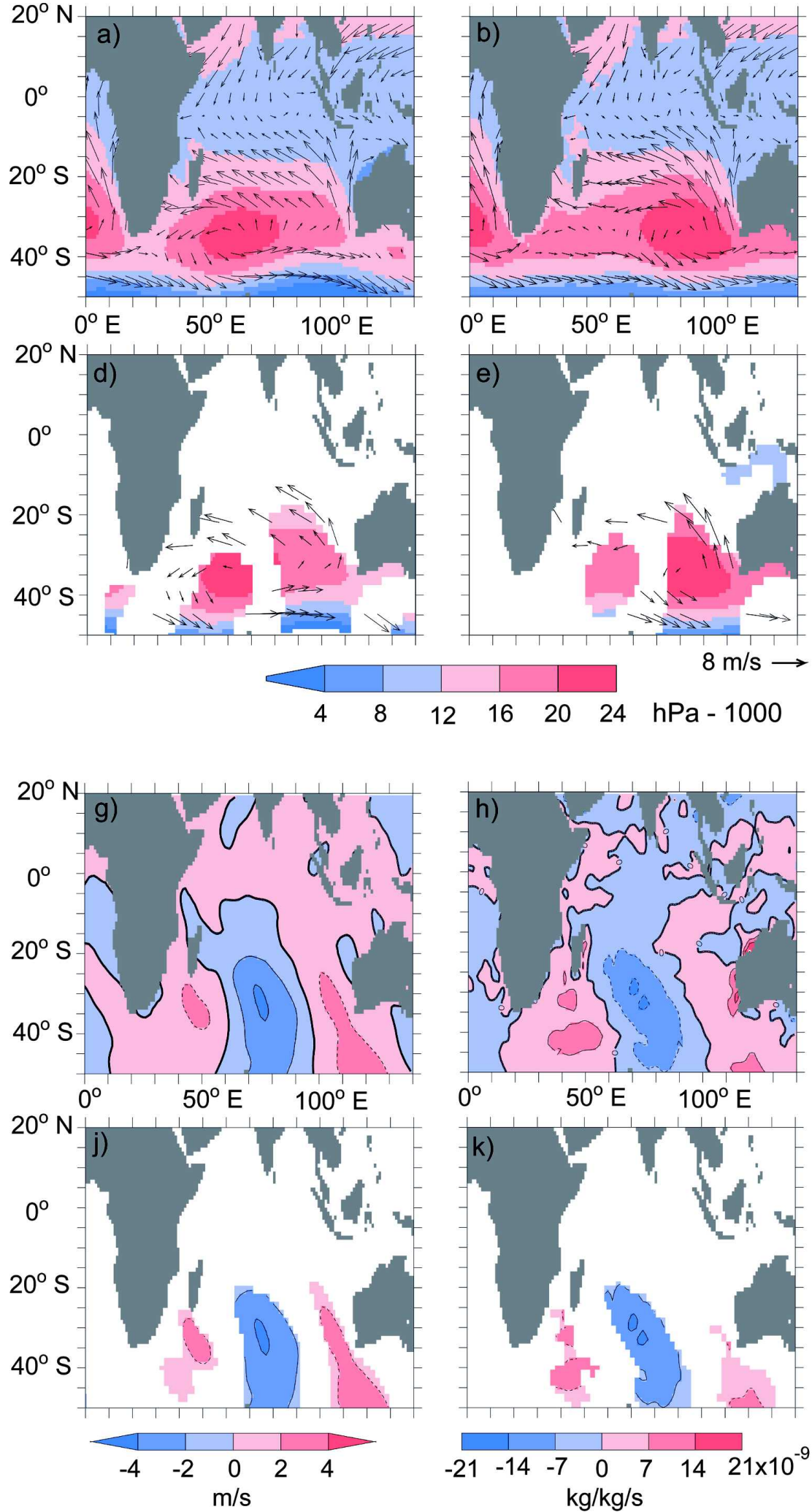
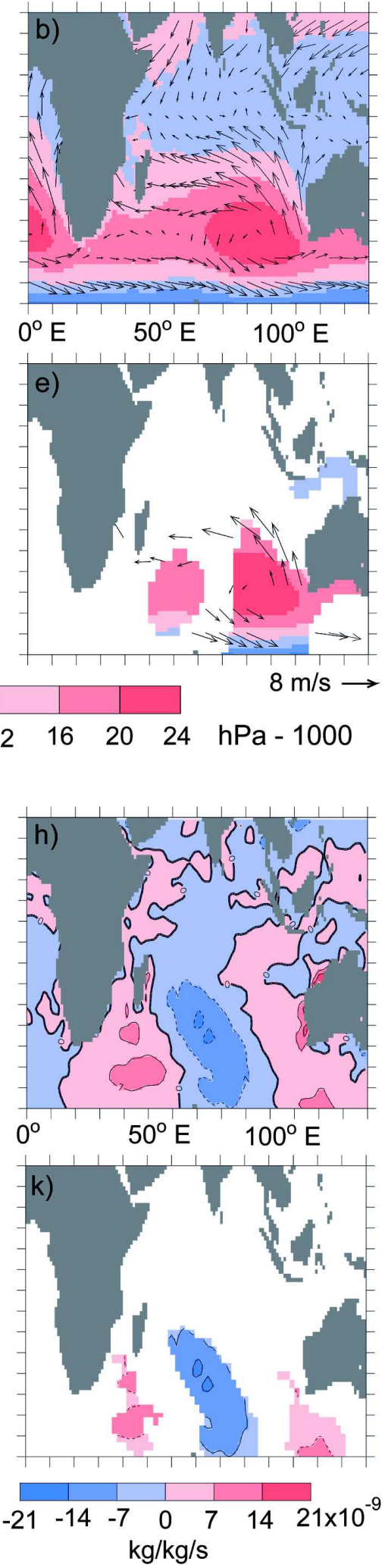
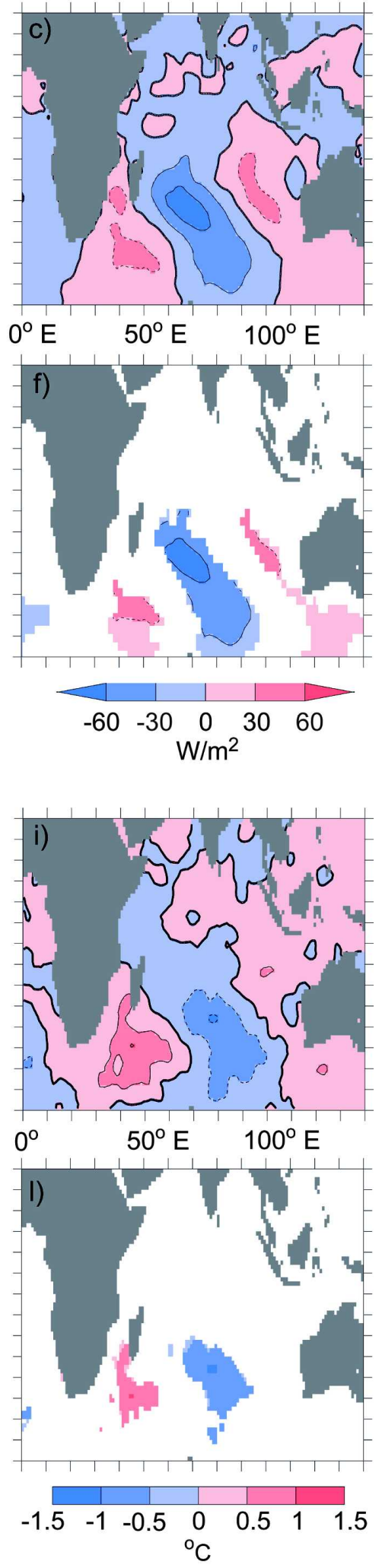

FIG. 7. (a) Mean SLP and wind composite during high western-low eastern SLP intervals. (b) As in (a), except for low western-high eastern SLP intervals. (c) Composite difference-high western minus high eastern SLP—of latent heat flux. (d)-(f) As in (a)-(c), respectively, except that only regions where the anomalies are significant at the $90 \%$ confidence level are shown. (g) Composite difference of southward wind. (h) Composite difference of $-\mathbf{V} \cdot \nabla_{h} q_{a}$. (i) Composite difference of SST anomalies. (j)-(l) As in (d)-(f), respectively, except that only regions where the anomalies are significant at the $90 \%$ confidence level are shown. 


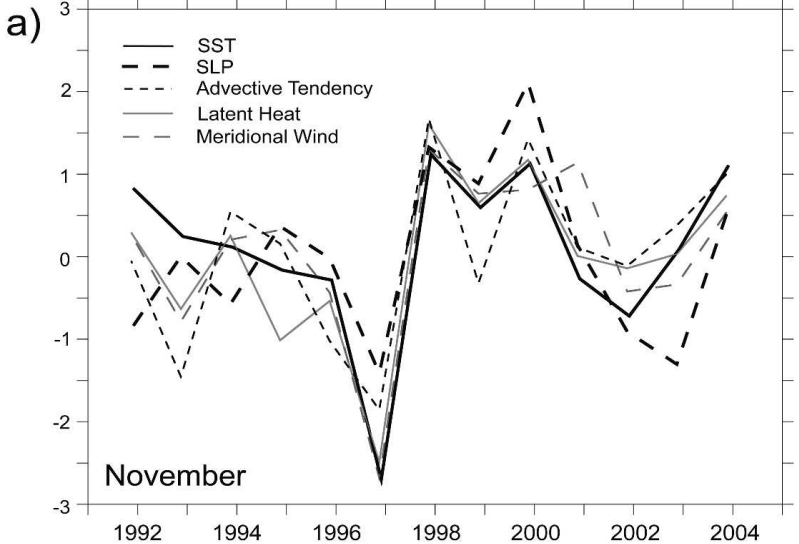

b)
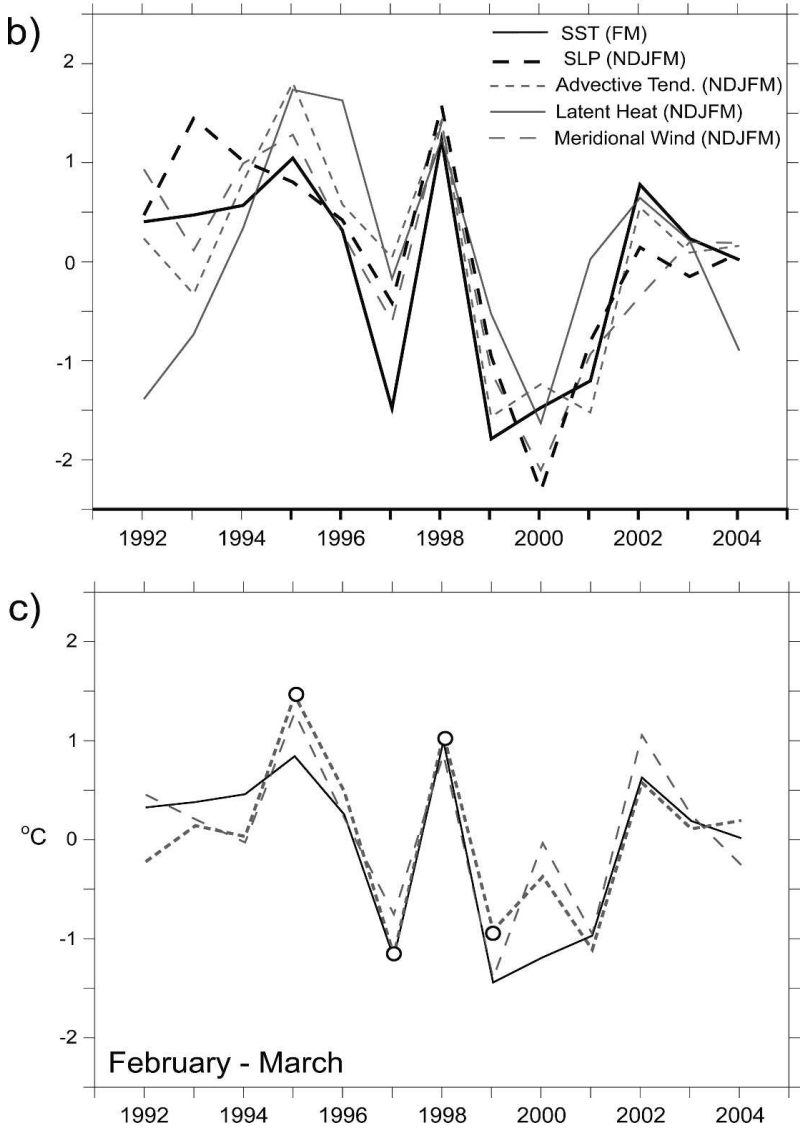

FIG. 8. (a) Southwestern to central basin differences of 30-day mean SST, SLP, advective water vapor tendency, latent heat flux, and meridional wind anomalies. The means are centered on 15 Nov for all variables except SST anomaly, which is centered on 30 Nov. Spatial averaging regions are listed in the text. These time series are normalized to have unit variance. Normalization factors are $1.0^{\circ} \mathrm{C}, 0.0041 \mathrm{~Pa}, 1.9 \times 10^{8} \mathrm{~s}^{-1}, 0.029 \mathrm{~W} \mathrm{~m}^{-2}$, and $0.67 \mathrm{~m} \mathrm{~s}^{-1}$, respectively. (b) Same indices as in (a), except that atmospheric variables are averaged from 1 Nov (of the year listed) to 30 Mar $($ year +1$)$ and SST is averaged from $1 \mathrm{Feb}($ year +1$)$ through 30 Mar (year +1$)$. Normalization factors are $1.2^{\circ} \mathrm{C}, 0.01 \mathrm{~Pa}, 3.6 \times$ $10^{8} \mathrm{~s}^{-1}, 0.09 \mathrm{~W} \mathrm{~m}^{-2}$, and $0.93 \mathrm{~m} \mathrm{~s}^{-1}$, respectively. (c) SST difference between the southwestern and central pole averaged over February and March. Spatial averaging regions are as defined in of $2500 \mathrm{~km}$ and wind anomalies of several $\mathrm{m} \mathrm{s}^{-1}$ ) will cause first-order changes in $\Delta q$ when acting over weekly or longer time scales.

Of course, changes in wind speed themselves cause changes in evaporation. To gain insight into the way in which wind speed and advection anomalies combine to produce a net effect on latent heat flux, we have devised a simple statistical model of the atmosphere. This boundary layer model may be pictured as a well-mixed column of air, of some fixed height $h_{a}$, in contact with the ocean and with the surrounding air masses. Tendencies in $q_{a}$ are described by

$$
\frac{\partial q_{a}(t)}{\partial t}=-K q_{a}(t)+C\left[q_{s}-q_{a}(t)\right],
$$

where $-K q_{a}$ represents a generic removal of moisture. This may be due to either precipitation within the column or mixing/advection with surrounding air mass. Removal of moisture is necessary for the model to have a nonzero $\Delta q$ in steady state. Here, $K$ is assumed to remain constant and is specified such that $\overline{\Delta q}$ matches the climatological NCEP value (appendix B). A similar parameterization of the upper boundary condition was used by Seager et al. (1995). The second term on the right-hand side of this equation represents the exchange of water vapor with the ocean; $C$ is derived from the standard latent heat flux parameterization (appendix B).

We assume the column starts in a steady-state flux condition with nonzero values of $\overline{\Delta q}, \overline{q_{a}}$, and $\bar{S}$ and is exposed to a nonzero field $\overline{\nabla_{h} q_{a}}$. We wish to find the latent heat flux anomaly caused by a step function perturbation in the low-level wind. This perturbation can initially change latent heat flux in two ways: it can change wind speed or it can advect $\nabla_{h} q_{a}$ and begin to change $\Delta q$. The wind speed anomaly created by a wind perturbation is

$$
S^{\prime}=\left[\left(\bar{U}+u^{\prime}\right)^{2}+\left(\bar{V}+v^{\prime}\right)^{2}\right]^{(1 / 2)}-\bar{S} .
$$

The new wind speed may be either larger or smaller than $\bar{S}$ depending upon the direction of the perturbation wind, relative to the climatological wind vector. The advective trend is simply

$$
A_{a}=-u^{\prime} \frac{\partial \bar{q}_{a}}{\partial x}-v^{\prime} \frac{\partial \bar{q}_{a}}{\partial y} .
$$

$\leftarrow$

this study (solid curve), as defined by Hermes and Reason (short dashed curve), and as defined by Behera and Yamagata (long dashed curve). Circles denote years that were cited as dipole years by Hermes and Reason, who considered data only up to year 1999. 

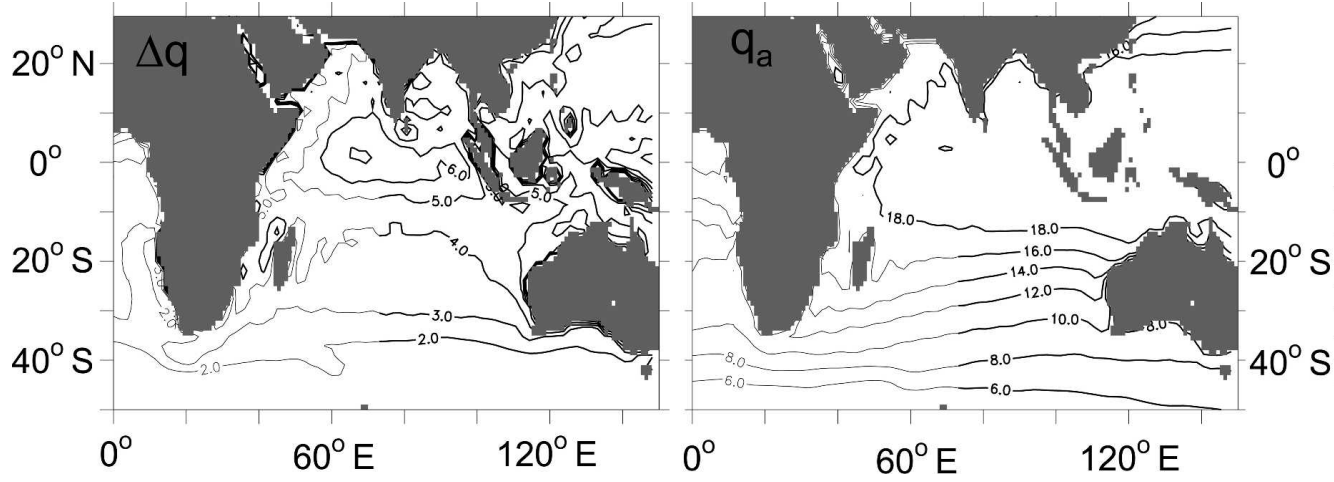

\section{Length Scale}

FIG. 9. (a) Annual mean $\Delta q, 1992-2004$. Contours are $1 \mathrm{~g} \mathrm{~kg}^{-1}$. (b) As in (a), except for $q_{a}$. (c) $\log _{10}(l / 100 \mathrm{~km})$, where

$$
l=\frac{\overline{\Delta q}}{\left|\partial q_{a} / \partial x+\partial q_{a} / \partial y\right|} .
$$

Climatologically, air is undersaturated and heat is lost from the ocean by evaporation. Dry air advected to a moist climate would tend to increase $\Delta q$ and increase evaporation. Moving moist air to a dry climate would do the opposite. Note that the same perturbation wind causes $A_{a}$ and $S^{\prime}$.

If the step function wind perturbation occurs at time $t=0$, then for all $t>0$

$$
\begin{aligned}
& S=\bar{S}+S^{\prime} \equiv S_{2}, \\
& C=\frac{C_{e} \cdot S_{2}}{h_{a}} \equiv C_{2},
\end{aligned}
$$

and $A_{a}$ appears as a term on the right-hand side of Eq. (8). As $q_{a}$ evolves, it has a back effect on the air-sea exchange of water vapor at the surface. Thus, this system is an ordinary differential equation for $q_{a}(t)$, assuming that $q_{s}, S_{2}$, and $C_{2}$ remain constant over the course of this perturbation. Strictly speaking, $q_{s}$ does not remain constant, but its variability has little effect on the results discussed here (see appendix B).

The solution to Eq. (8), for $t_{0}>0$, with initial condition $q_{a}(0)=\bar{q}_{a}$ and $S$ and $C$ given by Eqs. (11) and (12), is

$$
q_{a}\left(t_{0}\right)=\alpha e^{-\left(C_{2}+K\right) t_{0}}+\beta,
$$

with

$$
\begin{aligned}
& \alpha=\bar{q}_{a}-\beta, \\
& \beta=\frac{A_{a}+C_{2} q_{s}}{K+C_{2}},
\end{aligned}
$$

and

$$
q_{a}^{\prime}=q_{a}\left(t_{0}\right)-\bar{q}_{a}
$$

(see appendix B). We have chosen to use $t_{0}=7$ days, since this is near the decorrelation time scale of daily mean atmospheric perturbations. Using longer time scales changes the result little since the $e$-folding time scale $\left[1 /\left(C_{2}+K\right)\right]$ is generally $2-6$ days. The latent heat flux anomaly caused by $\left(u^{\prime}, v^{\prime}\right)$ is

$$
Q_{\mathrm{LH}}^{\prime}=C_{e} L_{e} \rho\left[S^{\prime}\left(\overline{\Delta q}-q_{a}^{\prime}\right)-\bar{S} \cdot q_{a}^{\prime}\right],
$$

which reduces to Eq. (2) when $S^{\prime} q_{a}^{\prime}$ is neglected. Trial and error has shown this to be a reasonable assumption in the cases considered here. This model, therefore, can be compared directly to the NCEP reanalysis data.

To evaluate the probability distribution of $S^{\prime}$ and $\Delta q^{\prime}$ associated with this system, we have performed a Monte Carlo simulation of the effects of random wind perturbations on latent heat flux variability. At each location, climatological mean $\bar{U}, \bar{V}, \bar{q}_{a}, \overline{\Delta q}$ should, and $\bar{\nabla}_{h} q_{a}$ values are specified from reanalysis data. Here, $h_{a}$ is set at $1500 \mathrm{~m}$. Five thousand pairs of zonal and meridional perturbation wind speeds are then applied to the model. The perturbation speeds are selected from a random normal distribution with zero mean and a standard deviation of $2 \mathrm{~m} \mathrm{~s}^{-1}$. Wind direction is selected from a random distribution. The choice of wind perturbation distribution is somewhat arbitrary, although other types of random distributions (e.g., standard deviation of $3 \mathrm{~m} \mathrm{~s}^{-1}$ or choosing wind speed perturbations from a nonnormal distribution) yielded very similar results to those presented below. It was found that the use of 5000 pairs was enough to obtain a statistically stable response. A pair of $S^{\prime}$ and $\Delta q^{\prime}$ anomalies was then found from the perturbation winds according to the equations above. To do this $\left(u^{\prime}, v^{\prime}\right)$ were first plugged into Eqs. (9) and (10) to get $S^{\prime}$ and $A_{a}$ and then these values, along with the climatological variables, are plugged into Eqs. (13) and (16) to yield $\Delta q^{\prime}$. Note that this model is forced by perturbations selected from the same random distribution at each location, and thus, 


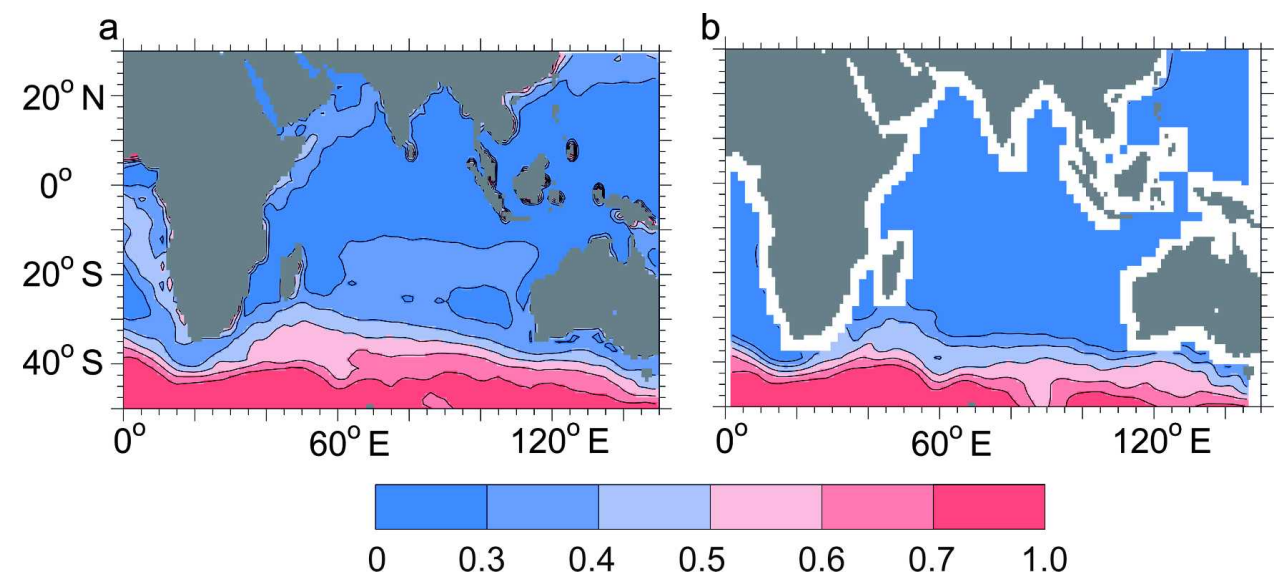

FIG. 10. Probability of $|R|>1.5$ determined from (a) NCEP reanalysis and (b) atmospheric mixed layer model. Red indicates that latent heat flux anomalies are most often determined mainly by $\Delta q$.

any spatial trends apparent in the results must be caused by the climatological parameters (e.g., $\overline{\Delta q}, \overline{\nabla_{h} q_{a}}$, $\bar{S}, \bar{U}$, and $\bar{V}$ ).

First, we determined whether one can expect either $\Delta q^{\prime}$ or $S^{\prime}$ to dominate the latent heat flux variability depending on location. To do this, the percentage of wind perturbations that caused $|R|>1.5$ [see Eq. (3)] was tabulated at each location. The probability of this occurrence $[\operatorname{Pr}(|R|>1.5)]$ shows a clear pattern of latitudinal variability (Fig. 10b). In the Tropics, $\operatorname{Pr}(|R|>$ 1.5 ) indicates that $S^{\prime}$ is by far the larger determinant of latent heat flux variability. It also indicates that in the middle to high latitudes, latent heat flux variability is primarily determined by $\Delta q^{\prime}$. The subtropics appear to be a transition between these two extremes, where both terms are important. This result can be partially understood by considering the latitudinal variation of $\bar{S}$ and $\overline{\Delta Q}$ (see Fig. 9). Generally speaking, $\bar{S}$ increases from the equator to the middle latitudes. This effectively reduces the magnitude of the latent heat flux anomaly associated with a given wind speed perturbation in the middle latitudes, relative to the Tropics. Also, $\overline{\Delta q}$ decreases with southward latitude, making $\Delta q$ anomalies more important in the subtropics and middle latitudes than they are in the Tropics. The magnitude of $\boldsymbol{\nabla}_{h} q_{a}$ is also an important factor. In the Indian Ocean Tropics, $\left|\nabla_{h} q_{a}\right|$ is small. ${ }^{3}$ Outside of the Tropics, there is a significant humidity gradient associated with the large SST gradient found throughout the subtropics and midlatitudes. Humidity advection becomes important here.

The general latitudinal trend seen in the model probability compares favorably to the trend found in re-

\footnotetext{
${ }^{3}$ This is not necessarily true in other basins. Near the Pacific cold tongue, for example, $\nabla_{h} q_{a}$ reaches subtropical values.
}

analysis data ${ }^{4}$ (Fig. 10a). Like the model, the reanalysis shows that $\Delta q^{\prime}$ effects are dominant in the middle latitudes and that both $S^{\prime}$ and $\Delta q^{\prime}$ are important in the subtropics. This comparison serves as partial confirmation that the processes included in the statistical model resemble those in the NCEP reanalysis. The model slightly under predicts the importance of $\Delta q$ variability in the subtropics relative to NCEP, suggesting that the model gives a conservative estimate of the importance of $\Delta q$ anomalies.

By what mechanism does the atmosphere create the 1998 and 1997 latent heat flux anomalies? We have already seen that both wind speed and $\Delta q$ anomalies are important. The methodology used to create the statistical model may also be used to estimate the latent heat anomaly created by the observed wind anomalies. The model-estimated latent heat anomalies in these years (Figs. 11a,f) show qualitatively similar patterns to those observed in the reanalysis (cf. Fig. 5), although the magnitudes are somewhat underpredicted. What is most important to this discussion is that 1998 shows less latent heat loss in the southwest and more latent heat loss midbasin, similarly to the NCEP estimate. Likewise, the opposite pattern is shown in 1997. By altering the wind anomalies applied to the model, we can test which characteristics drive the latent flux variation. The latent heat anomaly that results when the zonal wind anomaly was set to zero (Figs. 11b,g) and when the net wind speed anomaly (Figs. 11c,h) was set to zero remains remarkably similar to the original (Figs. 11a,f).

\footnotetext{
${ }^{4}$ For the reanalysis data, climatological monthly averages, interpolated to daily resolution, are used as the means. Deviations of the daily mean variables from this climatology are the anomalies.
} 

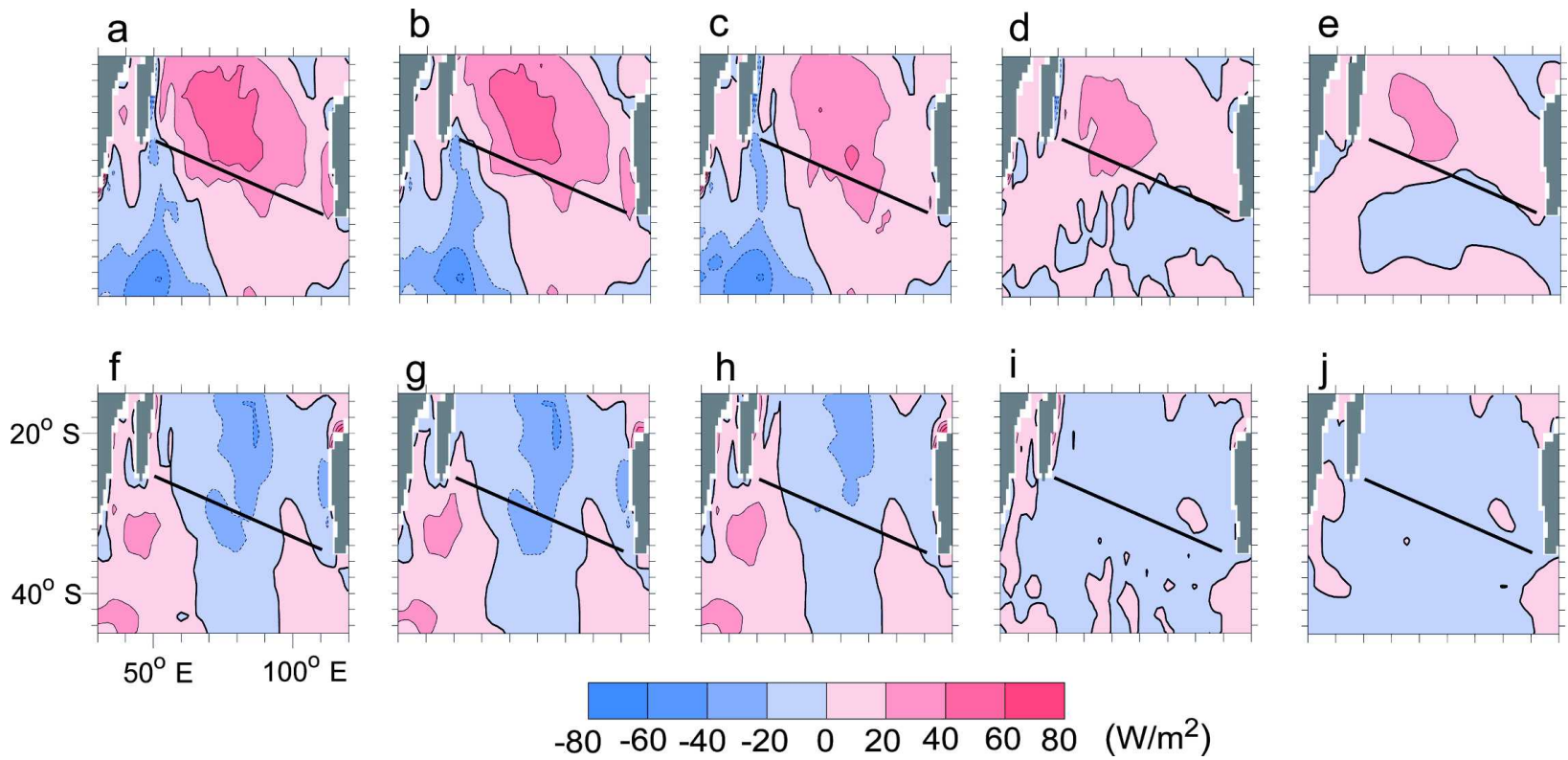

FIG. 11. The boundary layer model latent heat flux anomaly predicted from the November wind anomaly (a) 1997 and (f) 1998 . (b), (g) As in (a), (f), except zonal wind anomalies are neglected. (c), (h) As in (a), (f), except wind speed anomalies are neglected. (d), (i) As in (a), (f), except that meridional wind anomalies are neglected. (e), (j) As in (a), (f), except humidity advection is neglected. The straight black line roughly marks the division between regions of observed anomalous warming and cooling (see Fig. 2).

This means that neither zonal wind nor wind speed perturbations are dominant causes of the modeled latent heat anomaly. If either humidity advection or the meridional wind anomaly is set to zero, however (Figs. 11d,i for meridional wind anomaly; Figs. 11e, j for humidity advection), there is a drastic reduction in the latent heat anomaly. This means that these modelestimated latent heat anomalies are driven by humidity anomalies that are caused, in turn, by anomalous humidity advection. It appears that the central basin anomaly is more affected by the absence of this advection process in 1998 than in 1997. This is consistent with the results from section 5, which indicated that the 1998 latent heat flux anomaly is almost wholly caused by humidity variability, whereas wind speed makes a significant contribution to the central basin anomaly of November 1997.

\section{Summary and discussion}

The mechanisms responsible for basin-scale summer subtropical Indian Ocean SST anomalies have been revisited here. Case studies suggest that latent heat flux variability is the primary and immediate cause, but that it is at least as important to consider the role of variability of $\Delta q$ as of wind speed in order to understand the mechanism responsible [see Suzuki et al. (2004) for the case for wind speed variability]. Simple mixed layer model experiments indicate that the formation of thin summer ocean mixed layers is also important.
The role of $\Delta q$ variability has not been carefully investigated previously. Here, it has been shown that the dependence of latent heat flux variability on wind speed and $\Delta q$ anomalies tends to vary with latitude. Based on idealized atmospheric mixed layer model studies, $\Delta q$ variability is important in driving subtropical and higher latitude latent heat flux variations. Case study atmospheric mixed layer experiments have also shown that $\Delta q$ is of primary importance to the latent heat flux anomalies that drive the SST anomalies discussed here. This result is consistent with the analyses of NCEP reanalysis data presented here, which show that $\Delta q$ variability is a crucial factor in driving the latent heat flux anomalies in each case considered.

Meridional advection of boundary layer humidity appears to be the primary source of the $\Delta q$ variability of interest here. This direction is favored because the climatological near-surface horizontal humidity gradient tends to be meridional, being largely determined by SST, which has approximately zonal isotherms away from coasts. Based on typical climatological subtropical humidity gradients, meridional wind anomalies of several meters per second will cause first-order changes in $\Delta q$ over a week or longer. A major finding of the work reported here is that meridional wind anomalies (rather than zonal wind anomalies, which have been the focus of previous investigations) are pivotal to the SST anomaly formation mechanism.

Wind speed variability can, however, sometimes play 
an important role in driving the latent heat flux anomalies of interest. For example, off the east coast of Madagascar, wind speed variability accounted for about half of the latent heat flux anomaly in November 1997. Because climatological winds have a substantial northward component in this region, a southward wind anomaly will not only decrease wind speed but also will move moist air southward and decrease $\Delta q$. Thus, wind speed and humidity effects on latent heat flux tend to compliment each other in this region.

The meridional wind anomalies of interest appear to coincide with an extreme east or west location of the subtropical anticyclone. Anticyclones are prevalent features of near-surface subtropical atmospheric variability and efficiently transport dry air equatorward on their eastern flanks and moist air poleward on their western flanks.

The results shown here are consistent with the following SST anomaly formation mechanism. When the anticyclone is displaced to the western side of the basin, near Madagascar, the region directly south of Madagascar experiences relatively strong northerlies. These northerlies increase moisture advection to the region, which decreases $\Delta q$, which, in turn, decreases surface evaporation and eventually causes anomalously warm SST. In this position, the eastern side of the anticyclone advects drier midlatitude air to the central/eastern subtropics, cooling SST there by the opposite process. When the anticyclone is positioned near Australia (as in November 1997), the northerlies advect moist neartropical air to the central rather than southwestern portion of the basin. Anomalous warming then occurs in the central part of the basin. With the anticyclone more distant, the area south of Madagascar no longer has a source of near-tropical moisture and the SST ends up cooler than normal.

Why are latent heat and SST anomaly patterns generally oriented from the northwest to the southeast? The answer lies in the meridional wind field associated with an anticyclone. Rather than being split along a meridian, such that all winds to the east of the center of the anticyclone are southerly and winds to the west of the center are northerly, as in a classical radially symmetric vortex, the meridional wind field associated with a subtropical anticyclone has a northwest to southeast orientation. In other words, winds in the north-bynorthwest portion have a northward component and winds in the south-by-southeast portion have a southward component. The meridional wind anomalies that occur when the anticyclone migrates from one side of the basin to the other reflect this northwest to southeast orientation.

It is notable that previous studies concerned with these same SST anomalies have examined the formation mechanism at coarser resolution, using seasonal or longer averages of SST and latent heat flux data (cf. Suzuki et al. 2004; Hermes and Reason 2005). Averaged over these longer time scales, the bimodal variability of the anticyclone described here is not readily apparent. Results show, however, that the mechanism discussed here is applicable to seasonal time scales.

The fact that the subtropical SST anomalies sometimes persist over several months and sometimes occur in conjunction with El Niño and La Niña events suggests that a coupled air-sea mechanism influences the location of the subtropical anticyclone. We cannot speculate on the details of this mechanism at this time but would like to encourage future studies to look at this important aspect of southern subtropical Indian Ocean variability.

Acknowledgments. The authors would like to acknowledge helpful suggestions from two anonymous reviewers and helpful conversations with N. A. Bond. This publication is partially funded by the Joint Institute for the Study of the Atmosphere and Ocean (JISAO) under NOAA Cooperative Agreement NA17RJ1232.

\section{APPENDIX A}

\section{Comparing the Effects of $\Delta q^{\prime}$ and $S^{\prime}$ on $Q_{\mathbf{L H}}^{\prime}$}

The standard bulk latent heat flux parameterization (e.g., Large and Pond 1981) is

$$
Q_{\mathrm{LH}}=C_{e} L_{e} \rho S \Delta q .
$$

Although $C_{e}$ and $\rho$ are not technically constant, their variability is small compared to that of $S$ and $\Delta q$ and thus will be neglected.

A measure of the relative importance of $S$ and $\Delta q$ anomalies is found by first decomposing these variables into climatological monthly means $(\bar{S}, \overline{\Delta q})$ and deviations from these means $\left(S^{\prime}, \Delta q^{\prime}\right)$ :

$$
\begin{aligned}
S & =\bar{S}+S^{\prime} \quad \text { and } \\
\Delta q & =\overline{\Delta q}+\Delta q^{\prime} .
\end{aligned}
$$

The standard bulk latent heat flux parameterization thus may be written as

$$
Q_{\mathrm{LH}}=C_{e} L_{e} \rho\left(\overline{S \Delta q}+\bar{S} \Delta q^{\prime}+\overline{\Delta q} S^{\prime}+S^{\prime} \Delta q^{\prime}\right) .
$$

Trial and error has shown that, in the cases presented herein, the fourth term on the right-hand side of Eq. (A4) may be neglected with little loss of accuracy, so that

$$
\overline{Q_{\mathrm{LH}}} \approx C_{e} L_{e} \rho \overline{S \Delta q}
$$


and

$$
Q_{\mathrm{LH}}^{\prime} \approx C_{e} L_{e} \rho\left(\bar{S} \Delta q^{\prime}+\overline{\Delta q} S^{\prime}\right) .
$$

After dividing Eq. (23) by Eq. (A5), it follows that

$$
\frac{Q_{\mathrm{LH}}^{\prime}}{\overline{Q_{\mathrm{LH}}}} \frac{\Delta q^{\prime}}{\overline{\Delta q}}+\approx \frac{S^{\prime}}{\bar{S}} \text {. }
$$

\section{APPENDIX B}

\section{Solving for $q_{a}(t)$}

If $K, A_{a}, C$, and $q_{s}$ are constant, the equation

$$
\frac{\partial q_{a}}{\partial t}=-K q_{a}+A_{a}+C\left(q_{s}-q_{a}\right)
$$

is an ordinary differential equation for $q_{a}(t)$, with the general solution

$$
q_{a}(t)=\alpha e^{-C t}+\beta
$$

Here,

$$
C=\frac{C_{e} S}{h_{a}}
$$

and

$$
K=\frac{C_{e}}{h_{a}} \frac{\bar{q}_{a}-\bar{q}_{s}}{\bar{q}_{a}} .
$$

The initial condition, $q_{a}(0)=\bar{q}_{a}$, yields

$$
\bar{q}_{a}=\alpha+\beta .
$$

By Eq. (B2), at $t=\infty$,

$$
q_{a}(\infty)=\beta
$$

and since $\partial q_{a} / \partial t=0$ at $t=\infty$, Eq. (B1) yields

$$
q_{a}(\infty)=\frac{A_{a}}{C_{2}+K}+\frac{q_{s} C_{2}}{C_{2}+K}=\beta .
$$

Note that $q_{s}$ would not actually remain constant after the wind perturbation is applied since the wind anomaly causes a latent heat anomaly that alters SST. Here, $\partial q_{s} / \partial T$ at $T \approx 20^{\circ}-25^{\circ} \mathrm{C}$ is approximately $1 \mathrm{~g} \mathrm{~kg}^{1-}$ ${ }^{\circ} \mathrm{C}^{-1}$. The $\Delta q$ anomalies associated with the observed latent heat flux anomalies are on the order of $1 \mathrm{~g} \mathrm{~kg}^{-1}$, so changes in SST of $1^{\circ} \mathrm{C}$ are significant. Strictly speaking, the expected variations in $q_{s}$ are not small compared to this value. Including changes in $q_{s}$ in this model, however, has relatively little effect on $\Delta q^{\prime}$. This is because $q_{s}$ appears in Eq. (B7), which means that changes in $q_{s}$ drive similar changes in $q_{a}$. Since $K$ is significantly smaller than $C_{2}$ (generally less than $30 \%$ ), the changes in $q_{s}$ caused by anomalous heating of the surface force similar changes in $q_{a}$. Changes in SST are, therefore, of secondary importance to $\Delta q^{\prime}$.

\section{REFERENCES}

Alexander, M. A., I. Bladé, M. Newman, J. R. Lanzante, N.-C. Lau, and J. D. Scott, 2002: The atmospheric bridge: The influence of ENSO teleconnections on air-sea interaction over the global oceans. J. Climate, 15, 2205-2231.

Behera, S. K., and T. Yamagata, 2001: Subtropical SST dipole events in the southern Indian Ocean. Geophys. Res. Lett., 28, 327-330.

— P. S. Salvekar, and T. Yamagata, 2000: Simulation of interannual SST variability in the tropical Indian Ocean. $\mathrm{J}$. Climate, 13, 3487-3499.

Carton, J. A., X. Cao, B. S. Giese, and A. M. Da Silva, 1996: Decadal and interannual SST variability in the tropical Atlantic. J. Phys. Oceanogr., 26, 1165-1175.

— G. Ghepurin, X. Cao, and B. S. Giese, 2000: A simple ocean data assimilation analysis of the global upper ocean 19501995. Part I: Methodology. J. Phys. Oceanogr., 30, 294-309.

England, M. H., C. C. Ummenhofer, and A. Santoso, 2006: Interannual rainfall extremes over southwest Western Australia linked to Indian Ocean climate variability. J. Climate, 19, 1948-1969.

Fauchereau, N., S. Tzaska, Y. Richard, P. Roucou, and P. Camberlin, 2003: Sea-surface temperature co-variability in the southern Atlantic and Indian Oceans and its connections with the atmospheric circulation in the southern hemisphere. Int. J. Climatol., 23, 663-677.

Goddard, L., and N. E. Graham, 1999: Importance of the Indian Ocean for simulating rainfall anomalies over eastern and southern Africa. J. Geophys. Res., 104, 19 099-19 116.

Hermes, J. C., and C. J. C. Reason, 2005: Ocean model diagnosis if interannual coevolving SST variability in the southern Indian and south Atlantic Oceans. J. Climate, 18, 2864-2882.

Huang, B., and J. L. Kinter, 2002: Interannual variability in the tropical Indian Ocean. J. Geophys. Res., 107, 3199, doi:10.1029/2001JC001278.

Kalnay, E., and Coauthors, 1996: The NCEP/NCAR 40-Year Reanalysis Project. Bull. Amer. Meteor. Soc., 77, 437-471.

Large, W. G., and S. Pond, 1981: Open ocean momentum flux measurements in moderate to strong winds. J. Phys. Oceanogr., 11, 324-336.

Levitus, S., 1994: World Ocean Atlas 1994 CD Rom Sets. National Oceanographic Data Center Informal Rep. 13, 30 pp.

Mason, S. J., and M. R. Jury, 1997: Climatic variability and change over southern Africa: A reflection on underlying processes. Prog. Phys. Geogr., 21, 23-50.

Nicholson, S. E., 1997: An analysis of the ENSO signal in the tropical Atlantic and western Indian Oceans. Int. J. Climatol., 17, 345-375.

Paulson, C. A., and J. J. Simpson, 1977: Irradiance measurements in the upper ocean. J. Phys. Oceanogr., 7, 952-956.

Price, J. F., R. A. Weller, and R. Pinkel, 1986: Diurnal cycling: Observations on models of the upper ocean response to diurnal heating, cooling and wind mixing. J. Geophys. Res., 91 (C7), 8411-8427.

Reason, C. J. C., 1999: Interannual warm and cool events in the subtropical mid-latitude south Indian Ocean region. Geophys. Res. Lett., 26, 215-218.

- 2001: Subtropical Indian Ocean SST dipole events and southern African rainfall. Geophys. Res. Lett., 28, 215-218. 
—, and H. Mulenga, 1999: Relationships between South African rainfall and SST anomalies in the southwest Indian Ocean. Int. J. Climatol., 19, 1651-1673.

Reynolds, R. W., N. A. Rayner, T. M. Smith, D. C. Stokes, and W. Wang, 2002: An improved in situ and satellite SST analysis for climate. J. Climate, 15, 1609-1625.

Rocha, A., and I. Simmonds, 1997a: Interannual variability if south-eastern African summer rainfall. Part 1: Relationships with air-sea interaction processes. Int. J. Climatol., 17, 235265 .

and —, 1997b: Interannual variability if south-eastern African summer rainfall. Part 2: Modelling the impact of seasurface temperatures in rainfall and circulation. Int. J. Climatol., 17, 267-290.

Saji, N. H., and T. Yamagata, 2003: Structure of SST and surface wind variability during Indian Ocean dipole mode events: COADS observations. J. Climate, 16, 2735-2751.

Seager, R., Y. Kushnir, and M. A. Cane, 1995: On the heat flux boundary conditions for ocean models. J. Phys. Oceanogr., 25, 3219-3230.

Smith, S. R., D. M. Legler, and K. V. Verzone, 2001: Quantifying uncertainties in NCEP reanalyses using high-quality research vessel observations. J. Climate, 14, 4062-4072.

Suzuki, R., S. K. Behera, S. Iizuka, and T. Yamagata, 2004: Indian Ocean subtropical dipole simulated using a coupled general circulation model. J. Geophys. Res., 109, C09001, doi:10.1029/ 2003JC001974.

Walker, N. D., 1990: Links between South African summer rainfall and temperature variability of the Agulhas and Benguela current systems. J. Geophys. Res., 95, 3297-3319.

Xie, S.-P., H. Annamalai, F. A. Schott, and J. P. McCreary, 2002 : Structure and mechanisms of South Indian Ocean climate variability. J. Climate, 15, 864-878.

Yu, L., and M. M. Rienecker, 1999: Mechanisms for the Indian Ocean warming during the 1997-98 El Niño. Geophys. Res. Lett., 26, 735-738. 